\title{
Oscillators: Phenomenological Mappings and Analogies First Part: Mathematical Analogy and Chains
}

\author{
Katica Stevanović-Hedrih ${ }^{1)}$ \\ Ana Ivanović-Šašić ${ }^{2)}$ \\ Julijana Simonović ${ }^{3)}$ \\ Ljiljana Kolar-Anić ${ }^{4)}$ \\ Željko Čupić ${ }^{2}$
}

\begin{abstract}
New analytical and numerical results of dynamics for both linear and nonlinear system with two degrees of freedom are presented. For a mechanical chain system with two degrees of freedom, oscillations are investigated analytically and numerically with corresponding comparing between free and forced oscillatory dynamics of linear and nonlinear system. Also, energy analysis and transient energy between the mass particles in the system are discussed. Using Mihailo Petrović's theory of the mathematical phenomenology elements, phenomenological mappings in vibrations, signals, resonances and dynamical absorptions in models with two degrees of freedom - the abstractions of a different real system dynamics are identified and presented. Mathematical description of a chain mechanical system with two mass particles coupled by linear and nonlinear elastic springs and with two degrees of freedom is given. By analysis of corresponding solutions for free and forced vibrations, series of related two-frequency regimes and resonant states, as well as dynamical absorption states, are identified. Besides, by mathematical analogy and phenomenological mappings, the analysis of series of dynamics of other two degrees of freedom models dynamics (torsional system, double pendulum system, double electrical circuit) is performed
\end{abstract}

Key words: nonlinear dynamics, oscillations, free oscillations, forced oscillations, oscillator.

\section{Introduction}

$\mathrm{I}_{\mathrm{s}}^{\mathrm{N}}$ Neference [10] authored by Rašković D., the series of examples of electromechanical analogous vibration chain systems are presented. Mathematically described homogeneous chain dynamics and the corresponding system of linear ordinary differential equations are solved by a trigonometric method for different cases of both end conditions.

In References [1-3] different results of investigation of both free and forced oscillations of the system dynamics are presented, as well as the dynamics of hybrid systems which mathematical descriptions are analogous with mathematical description of the chain system dynamics.

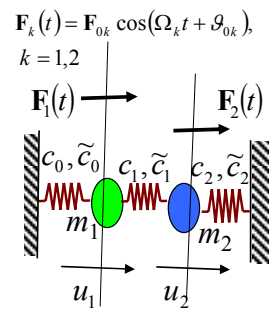

$a^{*}$

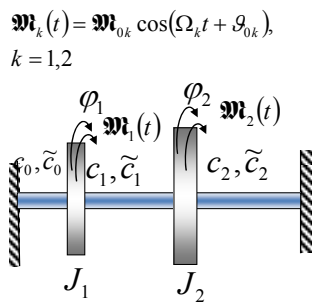

$b^{*}$

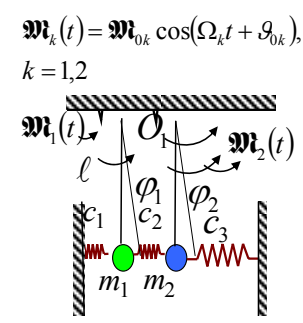

$\mathrm{c}^{*}$
$\mathbf{V}_{k}(t)=\mathbf{V}_{0 k} \cos \left(\Omega_{k} t+\vartheta_{0 k}\right)$

$k=1,2$

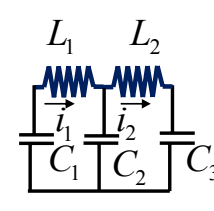

$\mathrm{d}^{*}$
Figure 1. System with two degrees of freedom. a* A mechanical system with two mass particles masses $m_{k}$, coupled by nonlinear elastic springs rigidities $c_{k}, \tilde{c}_{k}$ and two degrees of freedom expressed by generalized independent coordinates - translator displacements $u_{k}, k=1,2 ; \mathrm{b}^{*} \mathrm{~A}$ mechanical tensional system with two discs with mass axial inertia moments $\mathbf{J}_{k}, k=1,2$ coupled by nonlinear elastic shafts with torsional rigidities $c_{k}, \tilde{c}_{k}$ and two degrees of freedom expressed by corresponding generalized independent angular coordinates - angles of disc rotations $\varphi_{k}, k=1,2 ; \mathrm{c}^{*} \mathrm{~A}$ mechanical double-pendulum system with two mass particles with masses $m_{k}, k=1,2$ on the same length $\ell$ coupled with nonlinear spring with rigidity $c_{k}$ and two degrees of freedom expressed by generalized angular coordinates $\varphi_{k}$, $k=1,2$ and $\mathrm{d}^{*}$. An analogous electrical circuit system with two coil with inductances $L_{k}$ coupled by a nonlinear capacitor with the capacitances $c_{k}, \tilde{c}_{k}$ and two degrees of freedom expressed by generalized coordinates - electrical charge of a capacitor $q_{k}, k=1,2$ or velocity of generalized coordinate $i_{k}=d q_{k}$ $l d t, k=1,2$ intensity of electric current flowing through the branch circuits.

\footnotetext{
1) Mathematical Institute SANU, Knez Mihajlova 36/III, 11000 Belgrade, SERBIA

2) University of Belgrade, Institute of Chemistry, Technology and Metallurgy, Njegoševa 12, 11000 Belgrade, SERBIA

3) University of Niš, Faculty of Mechanical Engineering, Aleksandra Medvedova 14, 18000 Niš, SERBIA

4) University of Belgrade, Faculty of Physical Chemistry, Studentski trg 12-16, 11000 Belgrade, SERBIA

Correspondence to: Katica Stevanović-Hedrih; e-mail:khedrih@sbb.rs
} 
The qualitative and mathematical analogy presented in the books "Phenomenological mapping" [8] and "Elements of mathematical phenomenology" [9], both written by M. Petrović, are the theoretical basis of numerous results obtained in different scientific areas. See systems presented in Fig. 1.

References [5-7] by Mitropolyski contain series of different asymptotic methods of nonlinear mechanics known as the Krilov-Bogolyubv-Mireopolyskiy asymptotic method-applicable for investigation of the nonlinear phenomena around known solutions of corresponding linear or nonlinear differential equations.

In the following we shall analyze linear and nonlinear vibrations of a nonlinear system with two degrees of freedom oscillations together with a comparison of vibration properties and related phenomena [4].

\section{Vibration system with two degrees of freedom}

Let us consider linear and nonlinear dynamics of a two mass particle chain system in free and forced regimes. In Fig.2. $\mathrm{a}^{*}$ a chain mechanical system with two particles masses $m_{k}$, coupled by nonlinear elastic springs rigidities $c_{k}, \widetilde{c}_{k}$ and two degrees of freedom expressed by corresponding generalized independent coordinates translator displacements $u_{k}, k=1,2$ and with both fixed ends is presented. We propose that coefficients of nonlinear elasticity of the springs are cubic.

Then, we can investigate two cases of this two degrees of freedom chain system: 2 . a* both ends. of the chain are fixed and $2 . b^{*}$ one end of the chain is fixed and the second is free.

Kinetic and potential energies, for the cases when a chain is with both fixed ends (a*), or the left one fixed end and the right one free $\left(b^{*}\right)$, are:

$$
\begin{aligned}
& \text { 1. } \mathrm{a}^{*} \\
& \mathbf{E}_{k}=\frac{1}{2} m_{1} \dot{u}_{1}^{2}+\frac{1}{2} m_{2} \dot{u}_{2}^{2} \\
& \mathbf{E}_{k}=\frac{1}{2} m_{1} \dot{u}_{1}^{2}+\frac{1}{2} m_{2} \dot{u}_{2}^{2} \\
& \mathbf{E}_{p}=\frac{1}{2} c_{0}\left(u_{1}\right)^{2} \\
& +\frac{1}{2} c_{1}\left(u_{2}-u_{1}\right)^{2}+ \\
& \mathbf{E}_{p}=\frac{1}{2} c_{0}\left(u_{1}\right)^{2}+ \\
& +\frac{1}{2} c_{2}\left(u_{2}\right)^{2}+\frac{1}{4} \tilde{c}_{1}\left(u_{2}-u_{1}\right)^{4}+ \\
& +\frac{1}{2} c_{1}\left(u_{2}-u_{1}\right)^{2} \\
& +\frac{1}{4} \tilde{c}_{0}\left(u_{1}\right)^{4}+ \\
& +\frac{1}{4} \tilde{c}_{0}\left(u_{1}\right)^{4}+\frac{1}{4} \tilde{c}_{2}\left(u_{2}\right)^{4} \\
& +\frac{1}{4} \tilde{c}_{1}\left(u_{2}-u_{1}\right)^{4} \\
& \mathbf{F}_{1}(t)=\mathbf{F}_{01} \cos \left(\Omega_{1} t+\vartheta_{01}\right) \\
& \mathbf{F}_{2}(t)=\mathbf{F}_{02} \cos \left(\Omega_{2} t+\vartheta_{02}\right) \\
& \mathbf{F}_{1}(t)=\mathbf{F}_{01} \cos \left(\Omega_{1} t+\vartheta_{01}\right) \\
& \mathbb{S} c_{0}, \widetilde{c}_{0} \quad \longrightarrow \widetilde{N}
\end{aligned}
$$

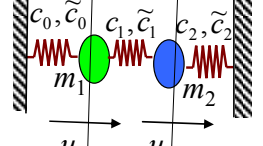

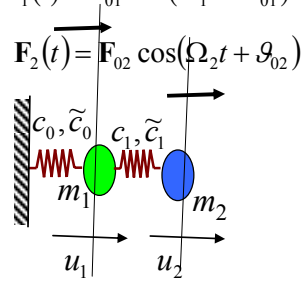$$
\mathrm{a}^{*}
$$

Figure 2. Two degrees of freedom system dynamics in like chain: $\left(a^{*}\right)$ a chain with both fixed ends and $\left(b^{*}\right)$ a chain with the left one fixed end and the right one free end. In both cases the external single frequency excitations: the first $\mathbf{F}_{1}(t)=\mathbf{F}_{01} \cos \left(\Omega_{1} t+\vartheta_{01}\right)$ and the second $\mathbf{F}_{2}(t)=\mathbf{F}_{02} \cos \left(\Omega_{2} t+\vartheta_{02}\right)$ are applied to the corresponding mass particles.

Differential equations of the linear two-mass particle dynamics:

$$
\begin{array}{cc}
1 . \mathrm{a}^{*} & 1 . \mathrm{b}^{*} \\
m_{1} \ddot{u}_{1}-c_{1}\left(u_{2}-u_{1}\right)+c_{0}\left(u_{1}\right)=0 & m_{1} \ddot{u}_{1}-c_{1}\left(u_{2}-u_{1}\right)+c_{0}\left(u_{1}\right)=0 \\
m_{2} \ddot{u}_{2}-c_{2}\left(-u_{2}\right)+c_{1}\left(u_{2}-u_{1}\right)=0 & m_{2} \ddot{u}_{2}+c_{1}\left(u_{2}-u_{1}\right)=0
\end{array}
$$

The previous system of differential equations presents free linear oscillations, which appear under the initial perturbations of the equilibrium state, by initial perturbation of the coordinates and initial velocities. Initial conditions of a linear system can be defined at the initial moment $t=0$, $u_{k}(0)=u_{0 k}$ and $\dot{u}_{k}(0)=\dot{u}_{0 k}, k=1,2$.

Next, we continue with the analysis of vibrations of the system with both fixed ends as in Fig. ${ }^{*}$ a. Corresponding matrix of inertia coefficients and rigidity coefficient for corresponding linear two mass particle chain systems, with defined kinetic and potential energies $\left(1^{*}\right.$ a $)$ as well as by a system of differential equations (2), (see Fig.2.a*), are:

$$
\mathrm{A}=\left(\begin{array}{ll}
m_{1} & \\
& m_{2}
\end{array}\right) \quad C=\left(\begin{array}{cc}
c_{0}+c_{1} & -c_{1} \\
-c_{1} & c_{1}+c_{2}
\end{array}\right)
$$

Frequency equation for the linear system defined by a system of differential equations $\left(2 . a^{*}\right)$, by using matrices (3) (see Refeence [42] by Raškoviċ) is in the following form:

$$
f\left(\omega^{2}\right)=\left|\mathbf{C}-\omega^{2} \mathrm{~A}\right|=0
$$

The roots of the frequency equation $f\left(\omega^{2}\right)=0,(4)$ are:

$$
\begin{aligned}
& \omega_{1,2}^{2}=\left[\frac{\left(c_{1}+c_{2}\right)}{2 m_{2}}+\frac{\left(c_{0}+c_{1}\right)}{2 m_{1}}\right] \\
& \mp \sqrt{\left[\frac{\left(c_{1}+c_{2}\right)}{2 m_{2}}+\frac{\left(c_{0}+c_{1}\right)}{2 m_{1}}\right]^{2}-\frac{c_{1} c_{0}+c_{2} c_{0}+c_{1} c_{2}}{m_{1} m_{2}}}
\end{aligned}
$$

and present a square of eigen circular frequencies of oscillatory linear chain system with two mass particles and with two degrees of freedom.

Cofactors of the considered system are:

$$
K_{21}^{(s)}=c_{1} \quad K_{22}^{(s)}=c_{0}+c_{1}-\omega_{s}^{2} m_{1}
$$

and they are obtained from a determinant (4) in the frequency equation as co-factors of the second order and corresponding column for corresponding eigen circular frequency (characteristic number).

General solutions for mass particle displacements, taking into account only free vibrations components (modes) are:

$$
\begin{gathered}
u_{k}(t)=K_{2 k}^{(1)} A_{1} \cos \left(\omega_{1} t+\alpha_{01}\right)+K_{2 k}^{(2)} A_{2} \cos \left(\omega_{2} t+\alpha_{02}\right), \\
k=1,2
\end{gathered}
$$

where $A_{s}$ and $\alpha_{0 s}, s=1,2$ are integral eigen main coordinate amplitudes and phases as unknown constants determined by the initial conditions.

Initial condition: Initial displacements $u_{k}(0)=u_{0 k}$ Initial Velocities $\dot{u}_{k}(0)=\dot{u}_{0 k}, k=1,2$. For the easiest calculations, we transform the solutions for displacements (denoted by: $A_{s}(=) A_{s} \cos \alpha_{0 s}$ and $B_{s}(=) A_{s} \sin \alpha_{0 s}, s=1,2$ ) in the form: 


$$
u_{k}(t)=\sum_{s=1}^{s=2} K_{2 k}^{(s)}\left(A_{s} \cos \omega_{s} t+B_{s} \sin \omega_{s} t\right), k=1,2
$$

and after using the initial conditions:

$$
\sum_{s=1}^{s=2} A_{s} K_{2 k}^{(s)}=u_{0 k} \quad \sum_{s=1}^{s=2} \omega_{s} B_{s} K_{2 k}^{(s)}=\dot{u}_{0 k}
$$

Since the modal matrix of the linear system $\left(2 . \mathrm{a}^{*}\right)$ is a matrix of determinant of previous both subsystems of the system (9), algebraic equations, along independent unknown eigen coefficients $A_{s}$ and $B_{s}, s=1,2$ it is in the form (see Reference [10] by Raškovic ):

$$
\begin{aligned}
& \mathbf{R}=\left(K_{2 k}^{(s)}\right)_{\rightarrow k=1,2}^{\downarrow}=\left(\begin{array}{ll}
K_{21}^{(1)} & K_{21}^{(2)} \\
K_{22}^{(1)} & K_{22}^{(2)}
\end{array}\right) \neq 0 \\
& \mathbf{R}=\left(\begin{array}{cc}
c_{1} & c_{1} \\
c_{0}+c_{1}-\omega_{1}^{2} m_{1} & c_{0}+c_{1}-\omega_{2}^{2} m_{1}
\end{array}\right) \neq 0
\end{aligned}
$$

Then the unknown constants $A_{s}$ and $B_{s}, s=1,2$ can be obtained by using the Cramer rule, in the following form:

$$
\begin{gathered}
|\mathbf{R}| A_{1}=K_{22}^{(2)} u_{01}-K_{21}^{(2)} u_{02}=\left(c_{0}+c_{1}-\omega_{2}^{2} m_{1}\right) u_{01}-c_{1} u_{02} \\
|\mathbf{R}| A_{2}=-K_{22}^{(1)} u_{01}-K_{21}^{(1)} u_{02}= \\
-\left(c_{0}+c_{1}-\omega_{1}^{2} m_{1}\right) u_{01}+c_{1} u_{02} \\
|\mathbf{R}| B_{1}=\frac{1}{\omega_{1}}\left(K_{22}^{(2)} \dot{u}_{01}-K_{21}^{(2)} \dot{u}_{02}\right)= \\
\frac{1}{\omega_{1}}\left[\left(c_{0}+c_{1}-\omega_{2}^{2} m_{1}\right) \dot{u}_{01}-c_{1} \dot{u}_{02}\right] \\
|\mathbf{R}| B_{2}=\frac{1}{\omega_{2}}\left(-K_{22}^{(1)} \dot{u}_{01}-K_{21}^{(1)} \dot{u}_{02}\right)= \\
\frac{1}{\omega_{2}}\left[-\left(c_{0}+c_{1}-\omega_{1}^{2} m_{1}\right) \dot{u}_{01}+c_{1} \dot{u}_{02}\right]
\end{gathered}
$$

Solutions of free displacement vibrations for known initial conditions are in the form:

$$
\begin{aligned}
u_{k}(t) & =\frac{1}{|\mathbf{R}|} K_{2 k}^{(1)}\left(K_{22}^{(2)} u_{01}-K_{21}^{(2)} u_{02}\right) \cos \omega_{1} t+ \\
& +\frac{1}{|\mathbf{R}|} K_{2 k}^{(2)}\left(-K_{22}^{(1)} u_{01}-K_{21}^{(1)} u_{02}\right) \cos \omega_{2} t+ \\
& +\frac{1}{|\mathbf{R}|} K_{2 k}^{(1)} \frac{1}{\omega_{1}}\left(K_{22}^{(2)} \dot{u}_{01}-K_{21}^{(2)} \dot{u}_{02}\right) \sin \omega_{1} t+ \\
& +\frac{1}{|\mathbf{R}|} K_{2 k}^{(2)} \frac{1}{\omega_{2}}\left(-K_{22}^{(1)} \dot{u}_{01}-K_{21}^{(1)} \dot{u}_{02}\right) \sin \omega_{2} t
\end{aligned}
$$

$$
k=1,2
$$

Previously obtained solutions are two-frequency and present a sum of collinear asynchronous two modes each with one of the obtained eigen circular frequencies defined by expressions (5).

By using the expressions (5) and (12) for the numerical data $m_{1}=1[\mathrm{~kg}], m_{2}=1.5[\mathrm{~kg}], c_{0}=0.5[5 \mathrm{~N} / \mathrm{cm}], c_{1}=1[5 \mathrm{~N} / \mathrm{cm}]$, $c_{2}=0.5[5 \mathrm{~N} / \mathrm{cm}]$ the following eigen circular frequencies are obtained: $\omega_{1}=0.63\left[\mathrm{sec}^{-1}\right]$ and $\omega_{2}=1.45\left[\mathrm{sec}^{-1}\right]$, and in Fig.3, time-history graphs for both mass particle displacement for free linear vibrations $\left(a^{*}\right)$ and corresponding phase trajectory graphs $\left(b^{*}\right)$ are presented using pure analytical expressions and MathCad software tools.

Free linear vibrations of a double mass chain linear system are with constant total mechanical energy, because system is conservative, and the sum of kinetic and potential energies is constant and equal to the initial values of total mechanical system energy:

$$
\mathbf{E}=\mathbf{E}_{k}+\mathbf{E}_{p}=\mathbf{E}_{0}=\mathbf{E}_{k 0}+\mathbf{E}_{p 0}=\text { const }
$$

Total mechanical energy of the linear system at the arbitrary moment of the system motion:

$$
\begin{aligned}
\mathbf{E} & =\frac{1}{2} m_{1} \dot{u}_{1}^{2}+\frac{1}{2} m_{2} \dot{u}_{2}^{2}+\frac{1}{2} c_{0}\left(u_{1}\right)^{2} \\
& +\frac{1}{2} c_{1}\left(u_{2}-u_{1}\right)^{2}+\frac{1}{2} c_{2}\left(u_{2}\right)^{2}
\end{aligned}
$$

Total mechanical energy of the linear system at the initial moment:

$$
\begin{aligned}
\mathbf{E}_{0}= & \frac{1}{2} m_{1} \dot{u}_{01}^{2}+\frac{1}{2} m_{2} \dot{u}_{02}^{2}+\frac{1}{2} c_{0}\left(u_{01}\right)^{2} \\
& +\frac{1}{2} c_{1}\left(u_{02}-u_{01}\right)^{2}+\frac{1}{2} c_{2}\left(u_{02}\right)^{2}
\end{aligned}
$$

which is the initial total energy of equilibrium system perturbation and which caused free oscillations of the linear system.

Solutions of the system of linear differential equations (2.a*) for linear system mass particle displacements are obtained numerically, too, by a direct numerical integration of these differential equations. The simulated results were performed using the MATLAB program package. The differential equations derived from the model were integrated using the ode15s solver. All numerical simulations were performed with the absolute and relative tolerance values equal to $1 \times 10^{-20}$ and $3 \times 10^{-12}$, respectively.
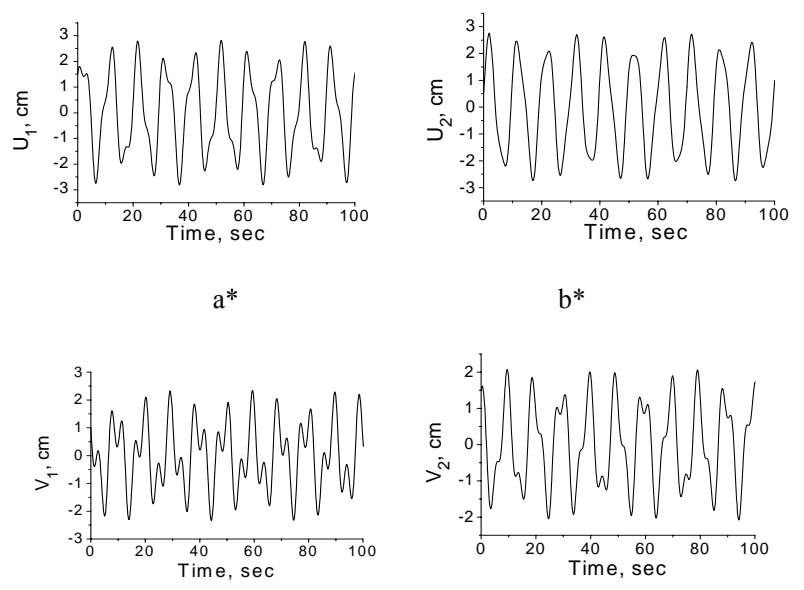

$c^{*}$

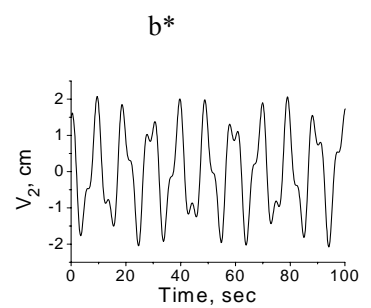

$d^{*}$

Figure 3. In $\mathrm{a}^{*}$ and $\mathrm{b}^{*}$ typical time history graph - evolution of two coordinates-mass particle displacements $u_{k}(t), k=1,2$ and $\mathrm{c}^{*}$ and $\mathrm{d}^{*}$ corresponding their velocities $v_{k}(t)=\dot{u}_{k}(t), k=1,2$.

In Figures 3.a* and $b^{*}$, typical time history graph evolution of two coordinates-mass particle displacements $u_{k}(t), k=1,2$, and in Figures 3.c* and $\mathrm{d}^{*}$ corresponding 
their velocities $v_{k}(t)=\dot{u}_{k}(t), \quad k=1,2, \quad$ for the given parameter values $m_{1}=1[\mathrm{~kg}], m_{2}=1.5[\mathrm{~kg}], c_{0}=0.5[\mathrm{~N} / \mathrm{cm}]$, $c_{1}=1[\mathrm{~N} / \mathrm{cm}], c_{2}=0.5[\mathrm{~N} / \mathrm{cm}]$ are presented.
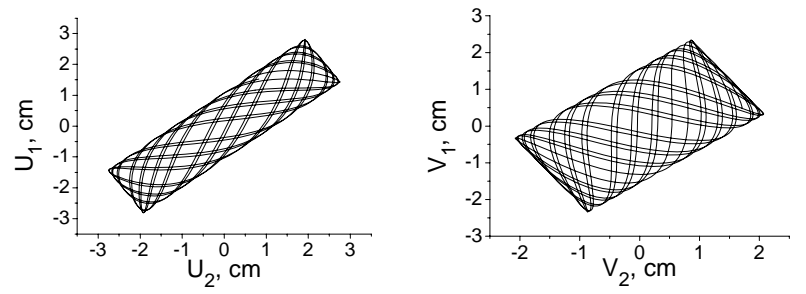

$\mathrm{a}^{*}$

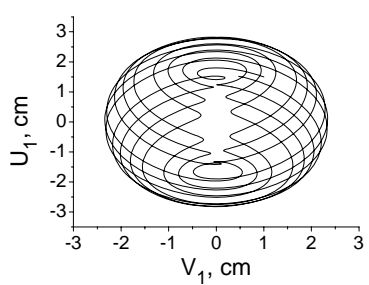

$\mathrm{c}^{*}$

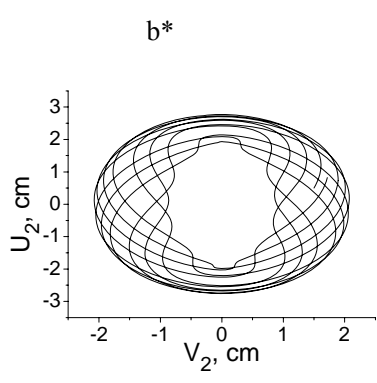

$\mathrm{d}^{*}$

Figure 4. Phase trajectory portraits of two-mass particle displacements and velocities for the same parameter values as for the system time -history graphs presented in Figures $3 . \mathrm{a}^{*}$ and $\mathrm{b}^{*}$ phase trajectories $\left(u_{1}(t), u_{2}(t)\right)$ and $\left(v_{1}(t)=\dot{u}_{1}(t), v_{2}(t)=\dot{u}_{2}(t)\right)$ and in $\mathrm{c}^{*}$ and $\mathrm{d}^{*}$ phase trajectories $\left(u_{1}(t), v_{1}(t)=\dot{u}_{1}(t)\right)$ and $\left(u_{2}(t), v_{2}(t)=\dot{u}_{2}(t)\right)$.

In Fig.4 the corresponding phase trajectory portraits of two-mass particle displacements and velocity for the same parameter values as for the system time -history graphs presented in Fig.3, given as: $m_{1}=1[\mathrm{~kg}], m_{2}=1.5[\mathrm{~kg}], c_{0}=0.5$ $[\mathrm{N} / \mathrm{cm}], c_{1}=1[\mathrm{~N} / \mathrm{cm}], c_{2}=0.5[\mathrm{~N} / \mathrm{cm}]$, are presented. In Figures 4. $\mathrm{a}^{*}$ and 4 . $\mathrm{b}^{*}$ the phase trajectories $\left(u_{1}(t), u_{2}(t)\right)$ and $\left(v_{1}(t)=\dot{u}_{1}(t), v_{2}(t)=\dot{u}_{2}(t)\right)$ are presented; In Figures 4.c* and $\mathrm{d}^{*}$ phase trajectories $\left(u_{1}(t), v_{1}(t)=\dot{u}_{1}(t)\right)$ and $\left(u_{2}(t), v_{2}(t)=\dot{u}_{2}(t)\right)$ are presented. Quasi-periodic, twofrequency behavior of the mass particle displacements is observed, corresponding to moving over the torus manifold of the system in phase space and corresponding subspaces phase planes.

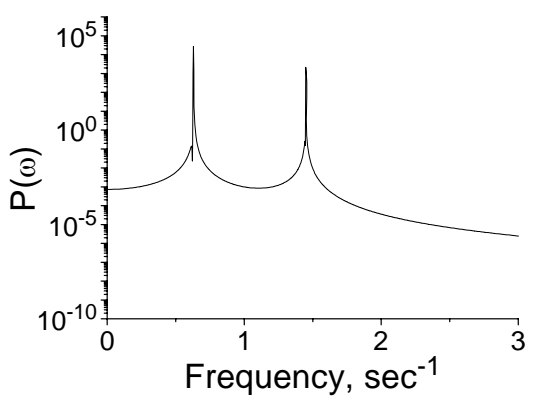

Figure 5. Power spectrum for the system from time series of the first coordinate $u_{1}(t)$ - the first mass particle displacement in the interval of time values between 0 and 10000, and time delay between points equal to 0.1

Power spectrum, presented in Fig.5, is calculated for this system from time series of the first coordinate $u_{1}(t)$-the first mass particle displacement in the interval of time values between 0 and 10000, and time delay between points equal to 0.1 . Hence, $10^{5}$ data points were used for the

calculation. Power spectrum is given below and the obtained sharp peaks are in agreement with a quasi-periodic nature of the system. Peak positions are in almost ideal agreement with the calculated values $\omega_{1}=0.64, \omega_{2}=1.46$ for given parameter values.

\section{Forced vibrations of the linear system. Resonance and dynamical absorption}

Differential equations of the linear two mass particle forced vibrations for the case that one external excitation $F_{01} \cos \Omega_{1} t$ is applied to the first mass particle and $F_{02} \cos \Omega_{2} t$ to the second mass particle are in the following form:

$$
\begin{aligned}
& m_{1} \ddot{u}_{1}-c_{1}\left(u_{2}-u_{1}\right)+c_{0}\left(u_{1}\right)=F_{01} \cos \Omega_{1} t \\
& m_{2} \ddot{u}_{2}-c_{2}\left(-u_{2}\right)+c_{1}\left(u_{2}-u_{1}\right)=F_{02} \cos \Omega_{2} t
\end{aligned}
$$

Where $F_{0 k}, k=1,2$ external excitation amplitude and $\Omega_{k}$, $k=1,2$ external excitation frequency.

For obtaining solutions for forced linear vibrations the previous system of differential equations is separated in two and expressed in the matrix forms:

$$
\begin{gathered}
\mathbf{A}\left\{\begin{array}{c}
\ddot{u}_{1} \\
\ddot{u}_{2}
\end{array}\right\}+\mathbf{C}\left\{\begin{array}{l}
u_{1} \\
u_{2}
\end{array}\right\}=\left\{\begin{array}{c}
F_{01} \\
0
\end{array}\right\} \cos \left(\Omega_{1} t+\theta_{01}\right) \\
\mathbf{A}\left\{\begin{array}{l}
\ddot{u}_{1} \\
\ddot{u}_{2}
\end{array}\right\}+\mathbf{C}\left\{\begin{array}{l}
u_{1} \\
u_{2}
\end{array}\right\}=\left\{\begin{array}{c}
0 \\
F_{02}
\end{array}\right\} \cos \left(\Omega_{2} t+\theta_{02}\right)
\end{gathered}
$$

Particular solutions of the previous subsystem are components of the particular solution of governing system of which solutions are obtained using principle of superposition of solutions for free vibrations and particular solutions of the previous subsystems.

Particular solutions are proposed in the following form:

$$
\left\{\begin{array}{l}
u_{1 p(1)}(t) \\
u_{2 p(1)}(t)
\end{array}\right\}=\left\{\begin{array}{l}
C_{1} \\
C_{2}
\end{array}\right\} \cos \left(\Omega_{1} t+\theta_{01}\right)
$$

and

$$
\left\{\begin{array}{l}
u_{1 p(2)}(t) \\
u_{2 p(2)}(t)
\end{array}\right\}=\left\{\begin{array}{l}
D_{1} \\
D_{2}
\end{array}\right\} \cos \left(\Omega_{2} t+\theta_{02}\right)
$$

After introducing the proposed solution in matrix differential equations (17) and (18), we obtain corresponding algebra subsystem along the unknown amplitudes $C_{k}$ and $D_{k}, k=1,2$, and it is possible to conclude that both algebra subsystems posses the same determinant of the subsystem in the following form:

$$
\Delta\left(\Omega^{2}\right)=\left(c_{0}+c_{1}-\Omega^{2} m_{1}\right)\left(c_{1}-\Omega^{2} m_{2}\right)-c_{1}^{2} \neq 0
$$

The unknown amplitudes $C_{k}$ and $D_{k}, k=1,2$ of the particular solutions of algebra equations are obtained by the Cramer rulein the following forms: for no resonance cases $\Delta\left(\Omega^{2}\right) \neq 0$ or $\Delta\left(\Omega_{1}^{2}\right) \neq 0$ and $\Delta\left(\Omega_{2}^{2}\right) \neq 0$ for $\Omega_{1} \neq \omega_{s}$ and $\Omega_{2} \neq \omega_{s}, s=1,2$ :

$$
C_{1}\left(\Omega_{1}^{2}\right)=\frac{F_{01}\left(c_{1}+c_{2}-\Omega_{1}^{2} m_{2}\right)}{\Delta\left(\Omega_{1}^{2}\right)}=\frac{\widetilde{C}_{1}\left(\Omega_{1}^{2}\right)}{\Delta\left(\Omega_{1}^{2}\right)},
$$




$$
\begin{gathered}
C_{2}\left(\Omega_{1}^{2}\right)=\frac{F_{01} c_{1}}{\Delta\left(\Omega_{1}^{2}\right)}=\frac{\widetilde{C}_{2}\left(\Omega_{1}^{2}\right)}{\Delta\left(\Omega_{1}^{2}\right)} \\
D_{2}\left(\Omega_{2}^{2}\right)==\frac{F_{02}\left(c_{0}+c_{1}-\Omega_{2}^{2} m_{1}\right)}{\Delta\left(\Omega_{2}^{2}\right)}=\frac{\widetilde{D}_{2}\left(\Omega_{2}^{2}\right),}{\Delta\left(\Omega_{2}^{2}\right)} \\
D_{1}\left(\Omega_{2}^{2}\right)=\frac{F_{02} c_{1}}{\Delta\left(\Omega_{2}^{2}\right)}=\frac{\widetilde{D}_{1}\left(\Omega_{2}^{2}\right)}{\Delta\left(\Omega_{2}^{2}\right)}
\end{gathered}
$$

In Fig.6( $\left.\mathrm{a}^{*}\right)$ the frequency graph of determinant $f\left(\Omega^{2}\right)=\Delta\left(\Omega^{2}\right)$ for the linear system forced vibrations are presented. In Fig.6( $\left.\mathrm{b}^{*}\right)$ the frequency graph $g\left(\Omega^{2}\right)=1 / \Delta\left(\Omega^{2}\right)$ of resonant frequencies and asymptotes of the amplitude frequency graphs for a double mass particle chain system are presented. From the frequency graphs, it is possible to see two asymptotes at the resonant frequencies with values equal to eigen circular frequencies of free linear vibrations. Number of asymptotes correspond and are equal to the number of degrees of freedom of the linear system.
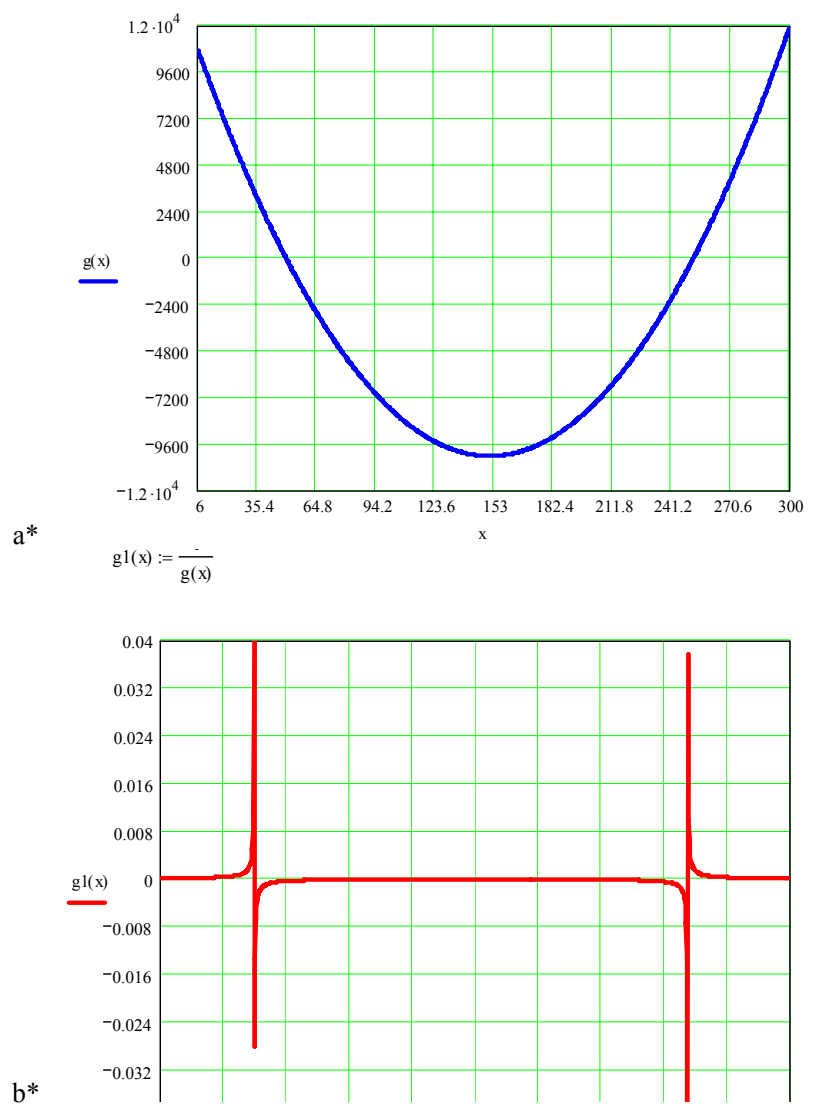

Figure 6. $\left(\mathrm{a}^{*}\right)$ Frequency graph of determinant $f\left(\Omega^{2}\right)=\Delta\left(\Omega^{2}\right)$ for the linear system forced vibrations, and $\left(b^{*}\right)$ Frequency graph $g\left(\Omega^{2}\right)=1 / \Delta\left(\Omega^{2}\right)$ of resonant frequencies and asymptotes of the amplitude frequency graphs for a double mass particle chain system.

In Fig.7 the amplitude-frequency curves $C_{1}\left(\Omega_{1}^{2}\right)$ and $C_{2}\left(\Omega_{1}^{2}\right)$ are shown for forced vibrations of the first mass particle $\left(\mathrm{a}^{*}\right)$ and the second mass particle $\left(\mathrm{b}^{*}\right)$ for the case that a single frequency external excitation is applied to the first mass particle of the two mass particle chain linear system. From the amplitude frequency curve $C_{1}\left(\Omega_{1}^{2}\right)$ for the first mass particle, at which the external single frequency excitation is applied, we can see two resonant frequencies $\Omega_{1 \text { res }}^{2}$ and $\Omega_{\text {rese }}^{2}$, and two asymptotes $C_{1}\left(\Omega_{1,2 \text { res }}^{2}\right) \rightarrow \infty$, and also, one frequency $\Omega_{1 a}^{2}$ at which the dynamical absorption appears, $C_{1}\left(\Omega_{1 a}^{2}\right)=0$.

From the amplitude frequency curve $C_{2}\left(\Omega_{1}^{2}\right)$, for the second mass particle at which there is no external single frequency excitation, we can also see two resonant frequency and two vertical asymptotes, but no frequency at which the dynamical absorption appears. We can conclude that in the forced regime at the amplitude - frequency curve $C_{1}\left(\Omega_{1}^{2}\right)$ of the first mass particle loaded by the external single frequency excitation appears at one frequency dynamical absorption, but in the frequency curve $C_{2}\left(\Omega_{1}^{2}\right)$ for the second mass particle no loaded directly by the external excitation there is no frequency at which appears the dynamical absorption. This is a fascinating dynamical state and single event and when directly loaded mass particle in forced regime with zero initial condition this mass particle is in the forced rest, and the second mass particle no directly loaded is in the forced vibration regime.
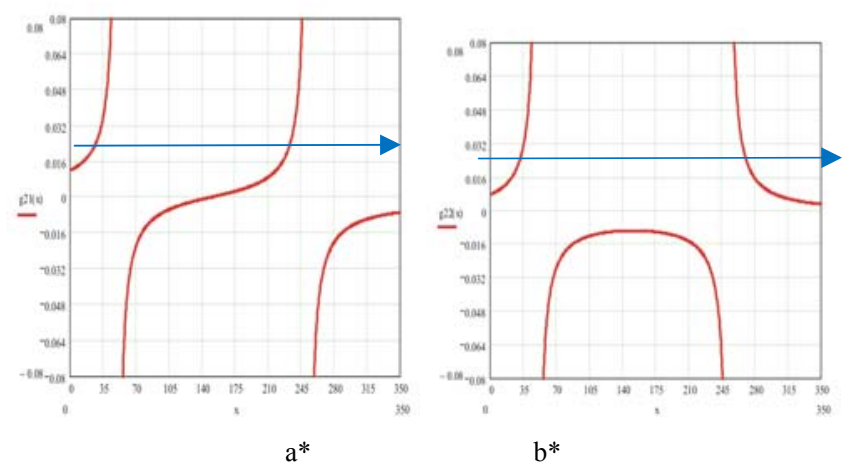

For $\Omega_{1}=\omega_{M}$, resonance case term $\mathrm{H}\left(\omega_{M} t\right) \rightarrow \infty$

$$
\mathrm{H}\left(\omega_{M} t\right)=\frac{\left(\omega_{M} t\right) \widetilde{C}_{k}\left(\omega_{M}^{2}\right)}{2 \omega_{M}^{2} \Delta^{(2)}\left(\omega_{M}^{2}\right)} \sin \left(\omega_{M} t+\theta_{01}\right)
$$

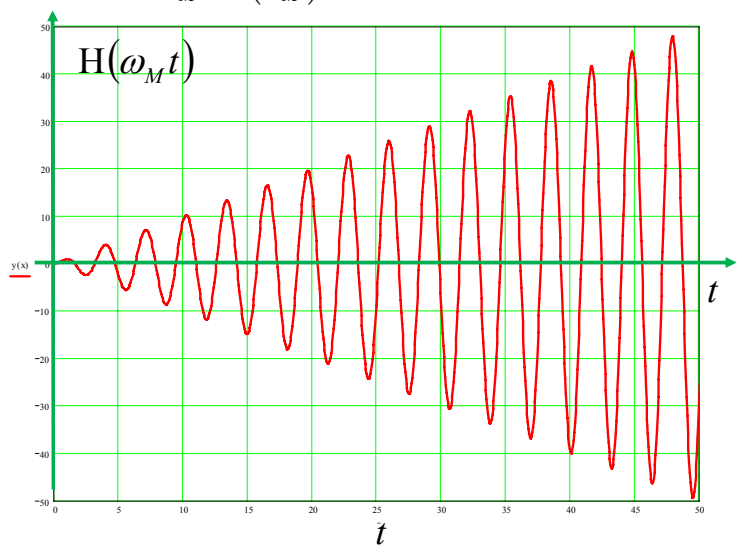

$c^{*}$

Figure 7. Amplitude-frequency curves: $\mathrm{a}^{*} C_{1}\left(\Omega_{1}^{2}\right)$ and $\mathrm{b}^{*} C_{2}\left(\Omega_{1}^{2}\right)$ for forced vibrations of the first mass particle $\left(\mathrm{a}^{*}\right)$ and the second mass particle $\left(b^{*}\right)$ for the case that single frequency external excitation is applied to the first mass particle of the two mass particle chain linear system. ( $\left.\mathrm{c}^{*}\right)$ Graph of increasing term in expression for mass particle displacements, $\mathrm{H}\left(\omega_{M} t\right)=\frac{\left(\omega_{M} t\right) \tilde{C}_{k}\left(\omega_{M}^{2}\right)}{2 \omega_{M}^{2} \Delta^{(2)}\left(\omega_{M}^{2}\right)} \sin \left(\omega_{M} t+\theta_{01}\right)$

Particular solutions of a matrix differential equation for two frequency forced linear vibrations and for no resonance 
cases $\Delta\left(\Omega^{2}\right) \neq 0$ or $\Delta\left(\Omega_{1}^{2}\right) \neq 0$ and $\Delta\left(\Omega_{2}^{2}\right) \neq 0$, for $\Omega_{1} \neq \omega_{s}$ and $\Omega_{2} \neq \omega_{s}, s=1,2$ are:

$$
\begin{aligned}
u_{1 p}(t)= & \frac{F_{01}\left(c_{1}+c_{2}-\Omega_{1}^{2} m_{2}\right)}{\Delta\left(\Omega_{1}^{2}\right)} \cos \left(\Omega_{1} t+\theta_{01}\right) \\
& +\frac{F_{09} c_{1}}{\Delta\left(\Omega_{2}^{2}\right)} \cos \left(\Omega_{2} t+\theta_{02}\right) \\
u_{2 p}(t) & =\frac{F_{01} c_{1}}{\Delta\left(\Omega_{1}^{2}\right)} \cos \left(\Omega_{1} t+\theta_{01}\right)+ \\
& +\frac{F_{02}\left(c_{0}+c_{1}-\Omega_{2}^{2} m_{1}\right)}{\Delta\left(\Omega_{2}^{2}\right)} \cos \left(\Omega_{2} t+\theta_{02}\right)
\end{aligned}
$$

General solutions taking into account free vibrations components of mass particle displacements are four frequency vibrations, two frequency with eigen circular frequencies modes and two frequency forced with two external excitation frequencies in linear vibration regimes and for no resonance cases $\Delta\left(\Omega^{2}\right) \neq 0$ or $\Delta\left(\Omega_{1}^{2}\right) \neq 0$ and $\Delta\left(\Omega_{2}^{2}\right) \neq 0$ for $\Omega_{1} \neq \omega_{s}$ and $\Omega_{2} \neq \omega_{s}, s=1,2$ are:

$$
\begin{aligned}
u_{1}(t)= & \sum_{s=1}^{s=2} K_{21}^{(s)}\left(A_{s} \cos \omega_{s} t+B_{s} \sin \omega_{s} t\right)+ \\
& +\frac{F_{01}\left(c_{1}+c_{2}-\Omega_{1}^{2} m_{2}\right)}{\Delta\left(\Omega_{1}^{2}\right)} \cos \left(\Omega_{1} t+\theta_{01}\right) \\
& +\frac{F_{09} c_{1}}{\Delta\left(\Omega_{2}^{2}\right)} \cos \left(\Omega_{2} t+\theta_{02}\right) \\
u_{2}(t)= & \sum_{s=1}^{s=2} K_{22}^{(s)}\left(A_{s} \cos \omega_{s} t+B_{s} \sin \omega_{s} t\right)+ \\
& +\frac{F_{01} c_{1}}{\Delta\left(\Omega_{1}^{2}\right)} \cos \left(\Omega_{1} t+\theta_{01}\right)+ \\
& \frac{F_{02}\left(c_{0}+c_{1}-\Omega_{2}^{2} m_{1}\right)}{\Delta\left(\Omega_{2}^{2}\right)} \cos \left(\Omega_{2} t+\theta_{02}\right)
\end{aligned}
$$

Initial conditions: Initial displacements $u_{k}(0)=u_{0 k}$ and initial velocities $\dot{u}_{k}(0)=\dot{u}_{0 k}, k=1,2$. Unknown integral constants $A_{s}$ and $B_{s}, s=1,2$ must satisfy the following conditions:

$$
\begin{aligned}
\sum_{s=1}^{s=2} A_{s} K_{21}^{(s)}= & u_{01}-\frac{F_{01}\left(c_{1}+c_{2}-\Omega_{1}^{2} m_{2}\right)}{\Delta\left(\Omega_{1}^{2}\right)} \cos \left(\theta_{01}\right) \\
& -\frac{F_{09} c_{1}}{\Delta\left(\Omega_{2}^{2}\right)} \cos \left(\theta_{02}\right) \\
\sum_{s=1}^{s=2} A_{s} K_{22}^{(s)} & =u_{02}-\frac{F_{01} c_{1}}{\Delta\left(\Omega_{1}^{2}\right)} \cos \left(\theta_{01}\right) \\
& -\frac{F_{02}\left(c_{0}+c_{1}-\Omega_{2}^{2} m_{1}\right)}{\Delta\left(\Omega_{2}^{2}\right)} \cos \left(\theta_{02}\right)
\end{aligned}
$$

$$
\begin{aligned}
\sum_{s=1}^{s=2} \omega_{s} B_{s} K_{21}^{(s)}= & \dot{u}_{01}+\frac{F_{01} \Omega_{1}\left(c_{1}+c_{2}-\Omega_{1}^{2} m_{2}\right)}{\Delta\left(\Omega_{1}^{2}\right)} \sin \left(\theta_{01}\right) \\
& +\frac{F_{09} \Omega_{2} c_{1}}{\Delta\left(\Omega_{2}^{2}\right)} \sin \left(\theta_{02}\right) \\
\sum_{s=1}^{s=1} \omega_{s} B_{s} K_{2 k}^{(s)} & =\dot{u}_{0 k}-\frac{F_{01} \Omega_{1} c_{1}}{\Delta\left(\Omega_{1}^{2}\right)} \sin \left(\theta_{01}\right) \\
& -\frac{F_{02} \Omega_{2}\left(c_{0}+c_{1}-\Omega_{2}^{2} m_{1}\right)}{\Delta\left(\Omega_{2}^{2}\right)} \sin \left(\theta_{02}\right)
\end{aligned}
$$

As the modal matrix of a linear system is a matrix of determinant of the previous both subsystem algebra equations (27) and (28) along independent unknown eigen coefficients $A_{s}$ and $B_{s}, s=1,2$ in the determinant form of modal matrix defined by (10) and using the Cramer rule, and for no resonance cases $\Delta\left(\Omega^{2}\right) \neq 0$ or $\Delta\left(\Omega_{1}^{2}\right) \neq 0$ and $\Delta\left(\Omega_{2}^{2}\right) \neq 0$ for $\Omega_{1} \neq \omega_{s}$ and $\Omega_{2} \neq \omega_{s}, s=1,2$, we obtain:

$$
\begin{aligned}
&|\mathbf{R}| A_{1}= K_{22}^{(2)} u_{01}-K_{21}^{(2)} u_{02} \\
&\left.-K_{22}^{(2)} / \frac{\tilde{C}_{1}\left(\Omega_{1}^{2}\right)}{\Delta\left(\Omega_{1}^{2}\right)} \cos \left(\theta_{01}\right)+\frac{\tilde{D}_{1}\left(\Omega_{2}^{2}\right)}{\Delta\left(\Omega_{2}^{2}\right)} \cos \left(\theta_{02}\right)\right\rangle+ \\
&+K_{21}^{(2)}\left\langle\frac{\tilde{C}_{2}\left(\Omega_{1}^{2}\right)}{\Delta\left(\Omega_{1}^{2}\right)} \cos \left(\theta_{01}\right)+\frac{\tilde{D}_{2}\left(\Omega_{2}^{2}\right)}{\Delta\left(\Omega_{2}^{2}\right)} \cos \left(\theta_{02}\right)\right\rangle \\
&|\mathbf{R}| A_{2}=-K_{22}^{(1)} u_{01}-K_{21}^{(1)} u_{02}+ \\
&\left.K_{22}^{(1)} / \frac{\tilde{C}_{1}\left(\Omega_{1}^{2}\right)}{\Delta\left(\Omega_{1}^{2}\right)} \cos \left(\theta_{01}\right)+\frac{\tilde{D}_{1}\left(\Omega_{2}^{2}\right)}{\Delta\left(\Omega_{2}^{2}\right)} \cos \left(\theta_{02}\right)\right\rangle+\quad(29) \\
&\left.+K_{21}^{(1)} / \frac{\tilde{C}_{2}\left(\Omega_{1}^{2}\right)}{\Delta\left(\Omega_{1}^{2}\right)} \cos \left(\theta_{01}\right)+\frac{\tilde{D}_{2}\left(\Omega_{2}^{2}\right)}{\Delta\left(\Omega_{2}^{2}\right)} \cos \left(\theta_{02}\right)\right\rangle \\
&|\mathbf{R}| B_{1}= \frac{1}{\omega_{1}}\left(K_{22}^{(2)} \dot{u}_{01}-K_{21}^{(2)} \dot{u}_{02}\right)+\frac{1}{\omega_{1}} K_{22}^{(2)} \\
&\left\langle\frac{\Omega_{1} \tilde{C}_{1}\left(\Omega_{1}^{2}\right)}{\Delta\left(\Omega_{1}^{2}\right)} \sin \left(\theta_{01}\right)+\frac{\Omega_{2} \tilde{D}_{1}\left(\Omega_{2}^{2}\right)}{\Delta\left(\Omega_{2}^{2}\right)} \sin \left(\theta_{02}\right)\right\rangle+ \\
&\left.+\frac{1}{\omega_{1}} K_{21}^{(2)} / \frac{\Omega_{1} \tilde{C}_{2}\left(\Omega_{1}^{2}\right)}{\Delta\left(\Omega_{1}^{2}\right)} \sin \left(\theta_{01}\right)+\frac{\Omega_{2} \tilde{D}_{2}\left(\Omega_{2}^{2}\right)}{\Delta\left(\Omega_{2}^{2}\right)} \sin \left(\theta_{02}\right)\right\rangle \\
&\left.+\frac{1}{\omega_{2}} K_{21}^{(1)} / \frac{\Omega_{1} \tilde{C}_{2}\left(\Omega_{1}^{2}\right)}{\Delta\left(\Omega_{1}^{2}\right)} \sin \left(\theta_{01}\right)+\frac{\Omega_{2} \tilde{D}_{2}\left(\Omega_{2}^{2}\right)}{\Delta\left(\Omega_{2}^{2}\right)} \sin \left(\theta_{02}\right)\right\rangle \\
&\left.\frac{1}{\omega_{2}} K_{22}^{(1)} \frac{\frac{1}{\omega_{2}}\left(-K_{22}^{(1)} \dot{u}_{01}-K_{21}^{(1)} \dot{u}_{02}\right)+}{\Delta\left(\Omega_{1}^{2}\right)} \sin \left(\theta_{01}\right)+\frac{\Omega_{2} \tilde{D}_{1}\left(\Omega_{2}^{2}\right)}{\Delta\left(\Omega_{2}^{2}\right)} \sin \left(\theta_{02}\right)\right\rangle+\quad(30)
\end{aligned}
$$

Solution for the first mass particle forced displacement vibrations for the known initial conditions and no resonant case, when $\Delta\left(\Omega^{2}\right) \neq 0$ or $\Delta\left(\Omega_{1}^{2}\right) \neq 0$ and $\Delta\left(\Omega_{2}^{2}\right) \neq 0$ for $\Omega_{1} \neq \omega_{s}$ and $\Omega_{2} \neq \omega_{s}, s=1,2$ is in the following form: 


$$
\begin{aligned}
&|\mathbf{R}| u_{1}(t)= K_{21}^{(1)}\left(K_{22}^{(2)} u_{01}-K_{21}^{(2)} u_{02}\right) \cos \omega_{1} t+K_{21}^{(2)}\left(-K_{22}^{(1)} u_{01}-K_{21}^{(1)} u_{02}\right) \cos \omega_{2} t+ \\
&+K_{21}^{(1)} \frac{1}{\omega_{1}}\left(K_{22}^{(2)} \dot{u}_{01}-K_{21}^{(2)} \dot{u}_{02}\right) \sin \omega_{1} t+K_{21}^{(2)} \frac{1}{\omega_{2}}\left(-K_{22}^{(1)} \dot{u}_{01}-K_{21}^{(1)} \dot{u}_{02}\right) \sin \omega_{2} t- \\
&-K_{21}^{(1)} K_{22}^{(2)}\left\langle\frac{\tilde{C}_{1}\left(\Omega_{1}^{2}\right)}{\Delta\left(\Omega_{1}^{2}\right)} \cos \left(\theta_{01}\right)+\frac{\tilde{D}_{1}\left(\Omega_{2}^{2}\right)}{\Delta\left(\Omega_{2}^{2}\right)} \cos \left(\theta_{02}\right)\right\rangle \cos \omega_{1} t- \\
&-K_{21}^{(1)} K_{21}^{(2)}\left\langle\frac{\tilde{C}_{2}\left(\Omega_{1}^{2}\right)}{\Delta\left(\Omega_{1}^{2}\right)} \cos \left(\theta_{01}\right)+\frac{\tilde{D}_{2}\left(\Omega_{2}^{2}\right)}{\Delta\left(\Omega_{2}^{2}\right)} \cos \left(\theta_{02}\right)\right\rangle \cos \omega_{1} t+ \\
&\left.+K_{21}^{(2)} K_{22}^{(1)} / \frac{\tilde{C}_{1}\left(\Omega_{1}^{2}\right)}{\Delta\left(\Omega_{1}^{2}\right)} \cos \left(\theta_{01}\right)+\frac{\tilde{D}_{1}\left(\Omega_{2}^{2}\right)}{\Delta\left(\Omega_{2}^{2}\right)} \cos \left(\theta_{02}\right)\right\rangle \cos \omega_{2} t+ \\
&\left.+K_{21}^{(2)} K_{21}^{(1)} / \frac{\tilde{C}_{2}\left(\Omega_{1}^{2}\right)}{\Delta\left(\Omega_{1}^{2}\right)} \cos \left(\theta_{01}\right)+\frac{\tilde{D}_{2}\left(\Omega_{2}^{2}\right)}{\Delta\left(\Omega_{2}^{2}\right)} \cos \left(\theta_{02}\right)\right\rangle \cos \omega_{2} t+ \\
&\left.+K_{21}^{(1)} \frac{1}{\omega_{1}} K_{22}^{(2)} / \frac{\Omega_{1} \tilde{C}_{1}\left(\Omega_{1}^{2}\right)}{\Delta\left(\Omega_{1}^{2}\right)} \sin \left(\theta_{01}\right)+\frac{\Omega_{2} \tilde{D}_{1}\left(\Omega_{2}^{2}\right)}{\Delta\left(\Omega_{2}^{2}\right)} \sin \left(\theta_{02}\right)\right\rangle \sin \omega_{1} t+ \\
&\left.+K_{21}^{(2)} \frac{1}{\omega_{2}} K_{21}^{(1)} / \frac{\Omega_{1} \tilde{C}_{2}\left(\Omega_{1}^{2}\right)}{\Delta\left(\Omega_{1}^{2}\right)} \sin \left(\theta_{01}\right)+\frac{\Omega_{2} \tilde{D}_{2}\left(\Omega_{2}^{2}\right)}{\Delta\left(\Omega_{2}^{2}\right)} \sin \left(\theta_{02}\right)\right\rangle \sin \omega_{2} t+ \\
&\left.+K_{21}^{(1)} \frac{1}{\omega_{1}} K_{21}^{(2)} / \frac{\Omega_{1} \tilde{C}_{2}\left(\Omega_{1}^{2}\right)}{\Delta\left(\Omega_{1}^{2}\right)} \sin \left(\theta_{01}\right)+\frac{\Omega_{2} \tilde{D}_{2}\left(\Omega_{2}^{2}\right)}{\Delta\left(\Omega_{2}^{2}\right)} \sin \left(\theta_{02}\right)\right\rangle \sin \omega_{1} t+ \\
&\left.+K_{21}^{(2)} \frac{1}{\omega_{2}} K_{22}^{(1)} / \frac{\Omega_{1} \tilde{C}_{1}\left(\Omega_{1}^{2}\right)}{\Delta\left(\Omega_{1}^{2}\right)} \sin \left(\theta_{01}\right)+\frac{\Omega_{2} \tilde{D}_{1}\left(\Omega_{2}^{2}\right)}{\Delta\left(\Omega_{2}^{2}\right)} \sin \left(\theta_{02}\right)\right\rangle \sin \omega_{2} t+ \\
& \cos \left(\Omega_{1} t+\theta_{01}\right)+\frac{F_{09} c_{1}}{\Delta\left(\Omega_{2}^{2}\right)} \cos \left(\Omega_{2} t+\theta_{02}\right) \\
&\left.+\frac{1}{2}\right) \\
&
\end{aligned}
$$

Resonant regimes appear when the external excitation frequency is equal to one of the two eigen circular frequencies of the basic system. After analysis of the component terms in general solutions, see expression (31), we can conlude that the expression contains the terms corresponding to pure free vibrations with eigen circular frequencies $\omega_{s}, s=1,2$ and terms depending on all four circular frequencies, two eigen circular frequencies $\omega_{s}, s=1,2$ and two external excitation frequencies $\Omega_{k}, k=1,2$. Lat us separate the term corresponding free two frequencies vibrations of the first mass particle displacement:

$$
\begin{aligned}
|\mathbf{R}| u_{1, \text { free })}(t)= & K_{21}^{(1)}\left(K_{22}^{(2)} u_{01}-K_{21}^{(2)} u_{02}\right) \cos \omega_{1} t+ \\
& +K_{21}^{(2)}\left(-K_{22}^{(1)} u_{01}-K_{21}^{(1)} u_{02}\right) \cos \omega_{2} t+ \\
& +K_{21}^{(1)} \frac{1}{\omega_{1}}\left(K_{22}^{(2)} \dot{u}_{01}-K_{21}^{(2)} \dot{u}_{02}\right) \sin \omega_{1} t+ \\
& +K_{21}^{(2)} \frac{1}{\omega_{2}}\left(-K_{22}^{(1)} \dot{u}_{01}-K_{21}^{(1)} \dot{u}_{02}\right) \sin \omega_{2} t
\end{aligned}
$$

Terms depending on all four circular frequencies, denoted in a sum by $u_{1,2}(t)$, for no resonant case, when $\Delta\left(\Omega^{2}\right) \neq 0$ or $\Delta\left(\Omega_{1}^{2}\right) \neq 0$ and $\Delta\left(\Omega_{2}^{2}\right) \neq 0$ for $\Omega_{1} \neq \omega_{s}$ and $\Omega_{2} \neq \omega_{s}, s=1,2$, between which are two eigen circular frequencies $\omega_{s}, s=1,2$ and two external excitation frequencies $\Omega_{k}, k=1,2$, in the form:

$$
\begin{aligned}
& |\mathbf{R}| u_{1,2}(t)=-K_{21}^{(1)} K_{22}^{(2)}\left\langle\frac{\tilde{D}_{1}\left(\Omega_{2}^{2}\right)}{\Delta\left(\Omega_{2}^{2}\right)} \cos \left(\theta_{02}\right)\right\rangle \cos \omega_{1} t- \\
& -K_{21}^{(1)} K_{21}^{(2)}\left(\frac{\tilde{D}_{2}\left(\Omega_{2}^{2}\right)}{\Delta\left(\Omega_{2}^{2}\right)} \cos \left(\theta_{02}\right)\right\rangle \cos \omega_{1} t+ \\
& +K_{21}^{(2)} K_{22}^{(1)}\left(\frac{\tilde{D}_{1}\left(\Omega_{2}^{2}\right)}{\Delta\left(\Omega_{2}^{2}\right)} \cos \left(\theta_{02}\right)\right\rangle \cos \omega_{2} t+ \\
& +K_{21}^{(2)} K_{21}^{(1)}\left(\frac{\tilde{D}_{2}\left(\Omega_{2}^{2}\right)}{\Delta\left(\Omega_{2}^{2}\right)} \cos \left(\theta_{02}\right)\right\rangle \cos \omega_{2} t+ \\
& +K_{21}^{(1)} \frac{1}{\omega_{1}} K_{22}^{(2)}\left\langle\frac{\Omega_{2} \tilde{D}_{1}\left(\Omega_{2}^{2}\right)}{\Delta\left(\Omega_{2}^{2}\right)} \sin \left(\theta_{02}\right)\right\rangle \sin \omega_{1} t+
\end{aligned}
$$




$$
\begin{aligned}
& +K_{21}^{(1)} \frac{1}{\omega_{1}} K_{21}^{(2)}\left\langle\frac{\Omega_{2} \tilde{D}_{2}\left(\Omega_{2}^{2}\right)}{\Delta\left(\Omega_{2}^{2}\right)} \sin \left(\theta_{02}\right)\right\rangle \sin \omega_{1} t+ \\
& +K_{21}^{(1)} \frac{1}{\omega_{1}} K_{22}^{(2)}\left(\frac{\Omega_{2} \tilde{D}_{1}\left(\Omega_{2}^{2}\right)}{\Delta\left(\Omega_{2}^{2}\right)} \sin \left(\theta_{02}\right)\right\rangle \sin \omega_{1} t+ \\
& +K_{21}^{(1)} \frac{1}{\omega_{1}} K_{21}^{(2)}\left(\frac{\Omega_{2} \tilde{D}_{2}\left(\Omega_{2}^{2}\right)}{\Delta\left(\Omega_{2}^{2}\right)} \sin \left(\theta_{02}\right)\right\rangle \sin \omega_{1} t+ \\
& +K_{21}^{(2)} \frac{1}{\omega_{2}} K_{22}^{(1)}\left(\frac{\Omega_{2} \tilde{D}_{1}\left(\Omega_{2}^{2}\right)}{\Delta\left(\Omega_{2}^{2}\right)} \sin \left(\theta_{02}\right)\right) \sin \omega_{2} t+ \\
& +K_{21}^{(2)} \frac{1}{\omega_{2}} K_{21}^{(1)}\left(\frac{\Omega_{2} \tilde{D}_{2}\left(\Omega_{2}^{2}\right)}{\Delta\left(\Omega_{2}^{2}\right)} \sin \left(\theta_{02}\right)\right\rangle \sin \omega_{2} t+ \\
& +\frac{F_{09} c_{1}}{\Delta\left(\Omega_{2}^{2}\right)} \cos \left(\Omega_{2} t+\theta_{02}\right)
\end{aligned}
$$

As it is visible from the expression (32), terms expressing component of the first mass particle displacement, denoted by $u_{1,2}(t)$ for the forced vibrations are four frequency vibrations, two frequency with eigen circular frequencies modes and two frequency forced with two external excitation frequencies, in linear vibration regimes and for resonance cases $\Delta\left(\Omega^{2}\right)=0$ or $\Delta\left(\Omega_{1}^{2}\right)=0$ and $\Delta\left(\Omega_{2}^{2}\right) \neq 0$ for $\Omega_{1}=\omega_{s}=\omega_{M}$ and $\Omega_{2} \neq \omega_{s}, s=1,2$ contain terms with a value: $0 / 0$, then we can separate a sum of the terms denoted as $u_{1,2 ; 1 \text { rez }}(t)=\left[u_{1,2}(t)\right]_{\Omega_{1}=\omega_{M}}=\frac{0}{0}$ : For the resonant case, a particular solution for the mass particle forced vibrations and known initial conditions contains, in the first part, terms from the expression for free vibrations with the finite elongations, and with three eigen circular frequencies and in the second part, a sum of the terms, now denoted by $u_{k, 2 ; 1 \text { rez }}\left(t, \Omega_{1}^{2}\right)$, depending on the set of eigen circular frequencies of free vibrations and of the external excitation circular frequency $\Omega_{1}^{2}=\omega_{M}^{2}=\omega_{s}^{2}, M=s=1,2$.

For the case when an external excitation circular frequency $\Omega_{1}$ is equal to one of the eigen circular frequency of free vibrations $\Omega_{1}=\omega_{M}$, from the set $\omega_{s}$, $\Omega_{1}^{2}=\omega_{M}^{2}=\omega_{s}^{2}, \quad M=s=1,2$ a sum of the terms from solution denoted by $\left[u_{1,2 ; 1 \text { rez }}\left(t, \Omega_{1}^{2}\right)\right]_{\Omega_{1}=\omega_{M}}$ takes undefined value $\left[u_{1,2 ; 1 \text { rez }}\left(t, \Omega_{1}^{2}\right)\right]_{\Omega_{1}=\omega_{M}}=\frac{0}{0}$ and is necessary to apply the L'Hôpital's rue to find the limit of this expression value $\left[u_{1,2 ; 1 \text { rez }}\left(t, \Omega_{1}^{2}\right)\right]_{\Omega_{1}=\omega_{M}}=\lim _{\Omega_{1} \rightarrow \omega_{M}} u_{1,2 ; \text { irez }}\left(t, \Omega_{1}^{2}\right) \quad$ (see Ref. [13]). For the resonant case, the obtained limits of expressions $u_{k, 2 ; 1 \text { rez }}\left(t, \Omega_{1}^{2}\right)$ contain terms in the following form $\mathrm{H}\left(\omega_{M} t\right)=\frac{\left(\omega_{M} t\right) \tilde{C}_{k}\left(\omega_{M}^{2}\right)}{2 \omega_{M}^{2} \Delta^{(2)}\left(\omega_{M}^{2}\right)} \sin \left(\omega_{M} t+\theta_{01}\right)$ which are oscillatory with increasing amplitudes with time and tends to be infinite with time $t \rightarrow \infty$. This is visible in Fig.7.c*.

For numerical integrations we transform the previous system for forced vibrations in the following:

$$
v_{1}=\dot{u}_{1} \quad m_{1} \dot{v}_{1}=+c_{1}\left(u_{2}-u_{1}\right)-c_{0}\left(u_{1}\right)+F_{01} \cos \Omega_{1} t
$$

$v_{2}=\dot{u}_{2} \quad m_{2} \dot{v}_{2}=+c_{2}\left(-u_{2}\right)-c_{1}\left(u_{2}-u_{1}\right)+F_{02} \cos \Omega_{2} t$

Typical time history evolution graphs $u_{1}(t)$ are given below in Figure 8. for $F_{01}=0.1$ and $F_{02}=0.15$ and two cases are given: one corresponding to resonant frequencies $\Omega_{1}=\omega_{1}, \Omega_{2}=\omega_{2}$, in Figure 8. $\mathrm{c}^{*}$, and the other for non commensurable frequencies $\Omega_{1}=\omega_{1} \cdot \pi, \quad \Omega_{2}=\omega_{2} \cdot \pi$ in Figure 8. $a^{*}$ and $b^{*}$.

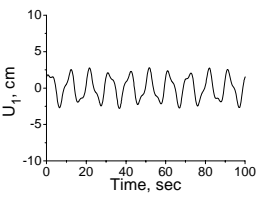

$\mathrm{a}^{*}$

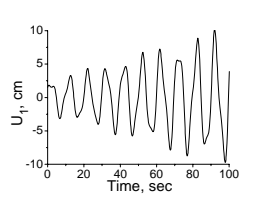

b*

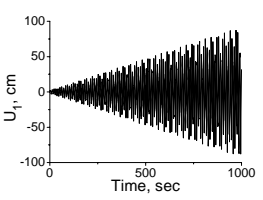

$\mathrm{c}^{*}$
Figure 8. In $a^{*}$ typical time history graph - evolution of the first coordinate-mass particle forced displacements $u_{1}(t)$ under the external excitation applied to both mass particle. $\mathrm{b}^{*}$ and $\mathrm{c}^{*}$ Resonant case.

In Fig.9 the phase trajectory portraits $\left(u_{1}(t), u_{2}(t)\right)$ of two-mass particle forced displacements for equal parameter values as for the system time - history graphs presented in Figures $8 \mathrm{a}^{*}$ and $8 \mathrm{c}^{*}$ are presented. In Fig.9.a* the phase trajectory $\left(u_{1}(t), u_{2}(t)\right)$ for no resonant forced oscillations and in Fig.9.b* phase trajectory $\left(u_{1}(t), u_{2}(t)\right)$ for resonant forced oscillations in a bounded interval of time are presented, and visible that elongations increase with duration of time interval in which system is under the external excitation loadings.

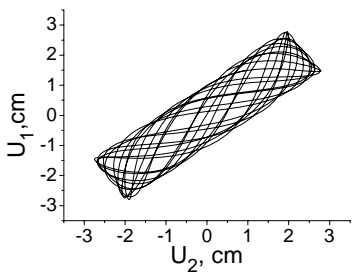

$a^{*}$

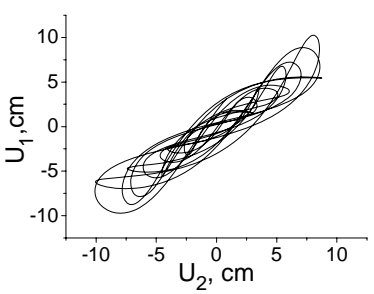

$\mathrm{b}^{*}$
Figure 9. Phase trajectory portraits $\left(u_{1}(t), u_{2}(t)\right)$ of two-mass particle forced displacements for the same parameter values as for the system time history graphs presented in Figures $8 \mathrm{a}^{*}$ and $8 \mathrm{c}^{*}$. $\mathrm{a}^{*}$ Phase trajectory $\left(u_{1}(t), u_{2}(t)\right)$ for no resonant forced oscillations and $\mathrm{b}^{*}$ Phase trajectory $\left(u_{1}(t), u_{2}(t)\right)$ for resonant forced oscillations in a bounded interval of time.

\section{Nonlinear free vibrations of two mass particle chain system}

Nonlinear differential equations for free vibrations of two mass particle chain system are in the following form:

$$
\begin{gathered}
m_{1} \ddot{u}_{1}-c_{1}\left(u_{2}-u_{1}\right)-\tilde{c}_{1}\left(u_{2}-u_{1}\right)^{3}+c_{0}\left(u_{1}\right)+\tilde{c}_{0}\left(u_{1}\right)^{3}=0 \\
m_{2} \ddot{u}_{2}-c_{2}\left(-u_{2}\right)-\tilde{c}_{2}\left(-u_{2}\right)^{3}+ \\
+c_{1}\left(u_{2}-u_{1}\right)+\tilde{c}_{1}\left(u_{2}-u_{1}\right)^{3}=0
\end{gathered}
$$

Free nonlinear vibrations of a double mass chain system are with constant total mechanical system energy, because the system is conservative, and a sum of the kinetic and potential energies is constant and equal to the initial values of the total mechanical system energy: 
$\mathbf{E}=\mathbf{E}_{k}+\mathbf{E}_{p}=\mathbf{E}_{0}=\mathbf{E}_{k 0}+\mathbf{E}_{p 0}=$ const. Total mechanical energy of the nonlinear system at the arbitrary moment for free vibrations is:

$$
\begin{aligned}
& \mathbf{E}=\frac{1}{2} m_{1} \dot{u}_{1}^{2}+\frac{1}{2} m_{2} \dot{u}_{2}^{2}+\frac{1}{2} c_{0}\left(u_{1}\right)^{2}+\frac{1}{2} c_{1}\left(u_{2}-u_{1}\right)^{2} \\
& +\frac{1}{2} c_{2}\left(u_{2}\right)^{2}+\frac{1}{4} \tilde{c}_{0}\left(u_{1}\right)^{4}+\frac{1}{4} \tilde{c}_{1}\left(u_{2}-u_{1}\right)^{4}+\frac{1}{4} \tilde{c}_{2}\left(u_{2}\right)^{4}
\end{aligned}
$$

We propose that nonlinear free vibrations of two mass particle chain systems with small nonlinearities are small and that approximation of the solution and nonlinear circular frequencies of nonlinear modes is possible to obtain in the first approximations.

For obtaining the first asymptotic approximation of the solution of the system of ordinary nonlinear differential equations, we start by a solution of the corresponding linearized system (see part 1, solutions (7) and (8)) in the following form:

$$
\begin{aligned}
& u_{1}(t)=K_{21}^{(1)} A_{1}(t) \cos \Phi_{1}(t)+K_{21}^{(2)} A_{2}(t) \cos \Phi_{2}(t) \\
& u_{2}(t)=K_{22}^{(1)} A_{1}(t) \cos \Phi_{1}(t)+K_{22}^{(2)} A_{2}(t) \cos \Phi_{2}(t)
\end{aligned}
$$

where amplitudes $A_{1}(t)$ and $A_{1}(t)$, and full phase $\Phi_{1}(t)=\omega_{1} t+\phi_{1}(t)$ and $\Phi_{2}(t)=\omega_{2} t+\phi_{2}(t)$ are the functions of time. We apply the Lagrange's method of variation constant and method of averaging, under the condition that the first derivatives of the proposed approximation of the solution are equal as these functions are constants (see reference [57]). After introducing the first and the second derivatives into the system of nonlinear differential equations (35) for the simpler case that the first and the third spring are nonlinear elastic, and the middle one is linear elastic (introducing denotations for $\tilde{c}_{1}=0, \frac{\tilde{c}_{0}}{m_{1}}=\varepsilon \kappa_{0} \quad$ and $\frac{\tilde{c}_{2}}{m_{2}}=\varepsilon \kappa_{2}$, with no loose of generality, but for the simpler expressions), we obtain two new additional conditions. Now we have four conditions along the unknown derivatives of the amplitudes $A_{1}(t)$ and $A_{1}(t)$, and difference of phases $\phi_{1}(t)$ and $\phi_{2}(t)$, and it is possible to obtain the following system of four ordinary differential equation in the following forms:

$$
\begin{aligned}
& \dot{A}_{1}(t)=\frac{\varepsilon \sin \Phi_{1}(t)}{\omega_{1}\left[K_{22}^{(2)} K_{21}^{(1)}-K_{21}^{(2)} K_{22}^{(1)}\right]} \\
& \left\langle\kappa_{0} K_{22}^{(2)}\left[K_{21}^{(1)} A_{1}(t) \cos \Phi_{1}(t)+K_{21}^{(2)} A_{2}(t) \cos \Phi_{2}(t)\right]^{3}\right\rangle- \\
& -\frac{\varepsilon \sin \Phi_{1}(t)}{\omega_{1}\left[K_{22}^{(2)} K_{21}^{(1)}-K_{21}^{(2)} K_{22}^{(1)}\right]} \\
& \left\langle\kappa_{2} K_{21}^{(2)}\left[K_{22}^{(1)} A_{1}(t) \cos \Phi_{1}(t)+K_{22}^{(2)} A_{2}(t) \cos \Phi_{2}(t)\right]^{3}\right\rangle
\end{aligned}
$$

$$
\begin{aligned}
& \dot{\varphi}_{1}(t)=\frac{\varepsilon \cos \Phi_{1}(t)}{\omega_{1} A_{1}(t)\left[K_{22}^{(2)} K_{21}^{(1)}-K_{21}^{(2)} K_{22}^{(1)}\right]} \\
& \left\langle\kappa_{0} K_{22}^{(2)}\left[K_{21}^{(1)} A_{1}(t) \cos \Phi_{1}(t)+K_{21}^{(2)} A_{2}(t) \cos \Phi_{2}(t)\right]^{3}\right\rangle- \\
& -\frac{\varepsilon \cos \Phi_{1}(t)}{\omega_{1} A_{1}(t)\left[K_{22}^{(2)} K_{21}^{(1)}-K_{21}^{(2)} K_{22}^{(1)}\right]} \\
& \left\langle\kappa_{2} K_{21}^{(2)}\left[K_{22}^{(1)} A_{1}(t) \cos \Phi_{1}(t)+K_{22}^{(2)} A_{2}(t) \cos \Phi_{2}(t)\right]^{3}\right\rangle \\
& \dot{A}_{2}(t)=\frac{\varepsilon \sin \Phi_{2}(t)}{\omega_{2}\left[K_{22}^{(1)} K_{21}^{(2)}-K_{22}^{(1)} K_{22}^{(2)}\right]} \\
& \left\langle\kappa_{2} K_{22}^{(1)}\left[K_{22}^{(1)} A_{1}(t) \cos \Phi_{1}(t)+K_{22}^{(2)} A_{2}(t) \cos \Phi_{2}(t)\right]^{3}\right\rangle \\
& \left\langle\kappa_{0} K_{22}^{(1)}\left[K_{21}^{(1)} A_{1}(t) \cos \Phi_{1}(t)+K_{21}^{(2)} A_{2}(t) \cos \Phi_{2}(t)\right]^{3}\right\rangle- \\
& \left.\left.\left\langle\kappa_{2}^{(1)}\left[K_{21}^{(1)} A_{1}(t) \cos \Phi_{1}(t)+K_{21}^{(1)}\left[K_{22}^{(1)} A_{1}(t) \cos \Phi_{1}(t)+K_{22}^{(2)} A_{2}(t) \cos \Phi_{2}(t)\right]^{3}\right\rangle\right) \cos \Phi_{2}(t)\right]^{3}\right\rangle \\
& \omega_{2}\left[K_{22}^{(1)} K_{21}^{(2)}-K_{22}^{(1)} K_{22}^{(2)}\right]
\end{aligned}
$$

Then, to the previous system the averaging actions are applied along the full phase $\Phi_{1}(t)=\omega_{1} t+\phi_{1}(t)$ and $\Phi_{2}(t)=\omega_{2} t+\phi_{2}(t) \quad$ in intervals $\Phi_{1}(t) \in[0,2 \pi]$ and $\Phi_{2}(t) \in[0,2 \pi]$ and the system of the averaged differential equations is:

$$
\begin{gathered}
\dot{A}_{1}(t)=0 \quad A_{1}(t)=A_{1}(0)=A_{01}=\text { const } \\
\dot{A}_{2}(t)=0 \quad A_{2}(t)=A_{2}(0)=A_{02}=\text { const } \\
\dot{\varphi}_{1}(t)=\frac{3 \varepsilon \kappa_{0} K_{21}^{(1)} K_{22}^{(2)}}{8 \omega_{1}\left[K_{22}^{(2)} K_{21}^{(1)}-K_{21}^{(2)} K_{22}^{(1)}\right]} \\
{\left[\left(K_{21}^{(1)} A_{1}(t)\right)^{2}+2\left(K_{21}^{(2)} A_{2}(t)\right)^{2}\right]-} \\
-\frac{3 \varepsilon \kappa_{2} K_{21}^{(2)} K_{22}^{(1)}}{8 \omega_{1}\left[K_{22}^{(2)} K_{21}^{(1)}-K_{21}^{(2)} K_{22}^{(1)}\right]} \\
\left.\left[\left[\left(K_{22}^{(1)} A_{1}(t)\right)^{2}+2 \mid\left(K_{22}^{(2)} A_{2}(t)\right)^{2}\right]\right]\right]
\end{gathered}
$$




$$
\begin{aligned}
\dot{\varphi}_{2}(t) & =\frac{3 \varepsilon \kappa_{0} K_{22}^{(1)} K_{21}^{(2)}}{8 \omega_{2}\left[K_{22}^{(1)} K_{21}^{(2)}-K_{22}^{(1)} K_{22}^{(2)}\right]} \\
& {\left[2\left(K_{21}^{(1)} A_{1}(t)\right)^{2}+\left(K_{21}^{(2)} A_{2}(t)\right)^{2}\right]-} \\
& -\frac{3 \varepsilon \kappa_{2} K_{22}^{(2)} K_{21}^{(1)}}{8 \omega_{2} A_{2}(t)\left[K_{22}^{(1)} K_{21}^{(2)}-K_{22}^{(1)} K_{22}^{(2)}\right]} \\
& {\left[2\left(K_{22}^{(1)} A_{1}(t)\right)^{2}+\left(K_{22}^{(2)} A_{2}(t)\right)^{2}\right] }
\end{aligned}
$$

Two circular frequencies of the nonlinear free vibrations in the first averaged approximations are: $\omega_{1 . \text { nonlinear }}=\dot{\Phi}_{1}(t)=\omega_{1}+\dot{\varphi}_{1}(t)$

and $\omega_{2 \text {.nonlinear }}=\dot{\Phi}_{2}(t)=\omega_{2}+\dot{\varphi}_{2}(t)$. It is possible to conclude that free nonlinear vibrations of two mass particle chain in the first approximation oscillate with two frequencies which are nonlinear functions of the initial nonlinear mode amplitudes, and that amplitude are constant in the first approximation during the vibrations and equal to the initial values.

Numerical experiment over the system of nonlinear differential equations (35) for free nonlinear vibrations is given with the parameter values $m_{1}=1[\mathrm{~kg}], m_{2}=1.5[\mathrm{~kg}]$, $c_{0}=0.5[\mathrm{~N} / \mathrm{cm}], c_{1}=1[\mathrm{~N} / \mathrm{cm}], c_{2}=0.5[\mathrm{~N} / \mathrm{cm}]$, as before and $\tilde{c}_{0}=0.005\left[\mathrm{~N} / \mathrm{cm}^{3}\right], \tilde{c}_{1}=0.01, \tilde{c}_{2}=0.005\left[\mathrm{~N} / \mathrm{cm}^{3}\right]$.
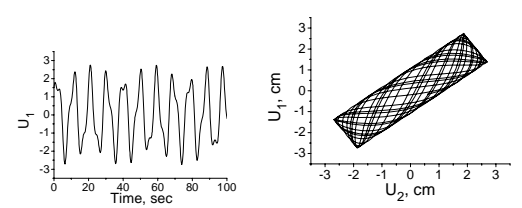

$b^{*}$

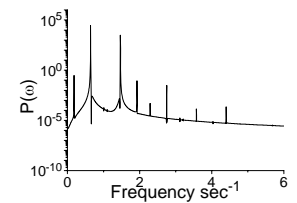

$\mathrm{c}^{*}$
Figure 10. $\left(a^{*}\right)$ Typical time history graph - evolution of the first mass particle coordinate-mass particle displacement $u_{1}(t)$ for free nonlinear vibrations. ( $\left.b^{*}\right)$ Phase trajectory portrait of two-mass particle displacements $\left(u_{1}(t), u_{2}(t)\right)$ for free nonlinear vibrations. ( $\left.\mathrm{c}^{*}\right)$ Power spectrum for the system from time series of the first coordinate $u_{1}(t)$-the first mass particle displacement in the interval of time values between 0 and 10000 , and time delay between points equal to 0.1 .

\section{Nonlinear forced vibrations of a two mass particle chain system}

Numerical analysis of the forced nonlinear system vibrations is based on the following system of ordinary nonlinear differential equations:

$$
v_{1}=\dot{u}_{1}
$$

$$
\begin{gathered}
m_{1} \dot{v}_{1}=+c_{1}\left(u_{2}-u_{1}\right)+\tilde{c}_{1}\left(u_{2}-u_{1}\right)^{3}-c_{0}\left(u_{1}\right) \\
-\tilde{c}_{0}\left(u_{1}\right)^{3}+F_{01} \cos \Omega_{1} t \\
v_{2}=\dot{u}_{2} \\
m_{2} \dot{v}_{2}=+c_{2}\left(-u_{2}\right)+\tilde{c}_{2}\left(-u_{2}\right)^{3}-c_{1}\left(u_{2}-u_{1}\right) \\
-\tilde{c}_{1}\left(u_{2}-u_{1}\right)^{3}+F_{02} \cos \Omega_{2} t
\end{gathered}
$$

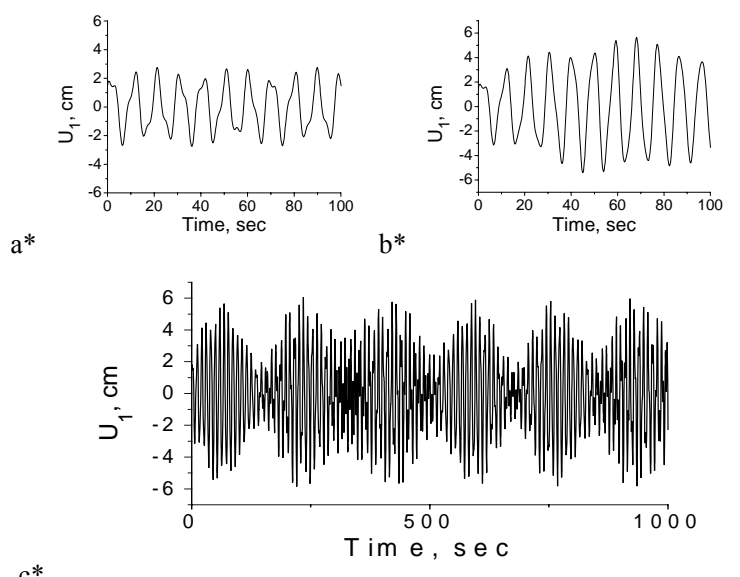

Figure 11. Typical time history graph - evolution of the first mass particle coordinate-mass particle displacement $u_{1}(t)$ for forced nonlinear vibrations for three no resonant cases. Forced frequency $\left(\mathrm{a}^{*}\right)$ outside of the resonant interval, $\left(\mathrm{b}^{*}\right)$ and $\left(\mathrm{c}^{*}\right)$ inside it.

Using the numerical results over the nonlinear system oscillations, for both, resonant and non-resonant cases series of the graphical presentations are given in Figures 11 and 12. As we can see, in the nonlinear case, double quasiperiodicity with a moderate increase in amplitudes is obtained as a response to the resonant frequency forcing. Namely, the amplitudes are approximately quasiperiodically increased and decreased.

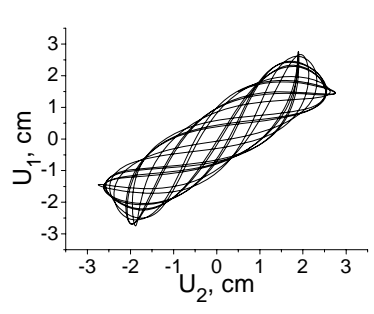

$\mathrm{a}^{*}$

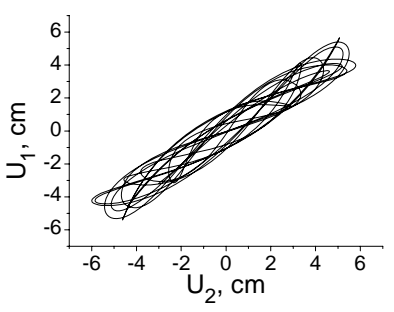

$b^{*}$

Figure 12. Phase trajectory portrait of two-mass particle displacements $\left(u_{1}(t), u_{2}(t)\right)$ for forced nonlinear vibrations and for no resonant cases. Forced frequency $\left(a^{*}\right)$ outside of the resonant interval, and $\left(b^{*}\right)$ inside it.

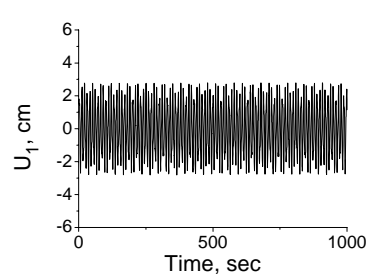

$a^{*}$

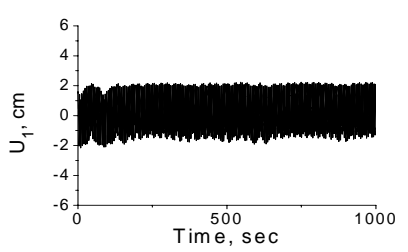

$\mathrm{c}^{*}$

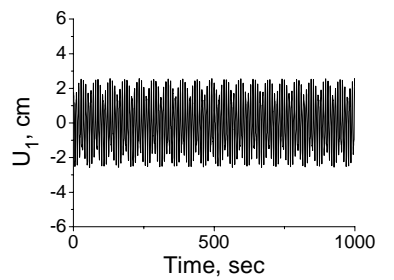

$b^{*}$

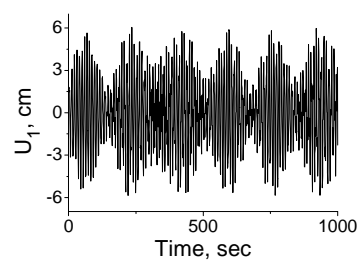

$d^{*}$ 


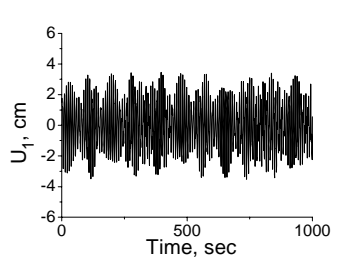

$\mathrm{e}^{*}$

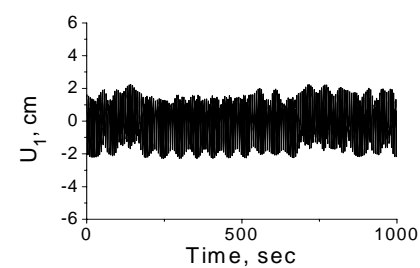

f*
Figure 13. Typical time history graphs - evolution of the first mass particle coordinate-mass particle displacement $u_{1}(t)$ for forced nonlinear vibrations for three no resonant cases: $\left(\mathrm{a}^{*}\right),\left(\mathrm{b}^{*}\right)$ and $\left(\mathrm{c}^{*}\right)$ and three resonant cases: $\left(\mathrm{d}^{*}\right),\left(\mathrm{e}^{*}\right)$ and $\left(\mathrm{f}^{*}\right)$.

In Fig.13 the typical time history graphs - evolution of the first mass particle coordinate-mass particle displacement $u_{1}(t)$ for forced nonlinear vibrations are presented. For three no resonant cases frequencies of the external excitation forces are: $\left(\mathrm{a}^{*}\right) \Omega_{1}=0,642 \pi$ and $\Omega_{2}=1,4669 \pi, \quad \tilde{c}_{0}=0.01\left[\mathrm{~N} / \mathrm{cm}^{3}\right], \quad \tilde{c}_{1}=0.01, \quad \tilde{c}_{2}=0.01$ $\left[\mathrm{N} / \mathrm{cm}^{3}\right] ; \quad\left(\mathrm{b}^{*}\right) \quad \Omega_{1}=0,642 \pi \quad$ and $\quad \Omega_{2}=1,4669 \pi, \tilde{c}_{0}=1$ $\left[\mathrm{N} / \mathrm{cm}^{3}\right], \tilde{c}_{1}=1, \tilde{c}_{2}=1\left[\mathrm{~N} / \mathrm{cm}^{3}\right] ;$ and $\left(\mathrm{c}^{*}\right) \Omega_{1}=0,642 \pi$ and $\Omega_{2}=1,4669 \pi, \tilde{c}_{0}=10\left[\mathrm{~N} / \mathrm{cm}^{3}\right], \tilde{c}_{1}=10, \tilde{c}_{2}=10\left[\mathrm{~N} / \mathrm{cm}^{3}\right]$; and three resonant cases: $\left(\mathrm{d}^{*}\right) \Omega_{1}=0,642$ and $\Omega_{2}=1,4669, \tilde{c}_{0}=$ $0.01\left[\mathrm{~N} / \mathrm{cm}^{3}\right], \tilde{c}_{1}=0.01, \tilde{c}_{2}=0.01\left[\mathrm{~N} / \mathrm{cm}^{3}\right] ; \quad\left(\mathrm{e}^{*}\right) \Omega_{1}=0,642$ and $\Omega_{2}=1,4669, \tilde{c}_{0}=1\left[\mathrm{~N} / \mathrm{cm}^{3}\right], \quad \tilde{c}_{1}=1, \tilde{c}_{2}=1\left[\mathrm{~N} / \mathrm{cm}^{3}\right]$; and $\left(\mathrm{f}^{*}\right) \Omega_{1}=0,642$ and $\Omega_{2}=1,4669, \tilde{c}_{0}=10\left[\mathrm{~N} / \mathrm{cm}^{3}\right], \tilde{c}_{1}=$ $10, \tilde{c}_{2}=10\left[\mathrm{~N} / \mathrm{cm}^{3}\right]$;

\section{Concluding Remarks}

New analytical and numerical results of the linear and nonlinear dynamics of two degrees of freedom system analysis are presented. For a mechanical chain system with two degrees of freedom the oscillations in non-resonant as well as in resonant case expressions of solution are derived. Using the direct numerical experiment over the corresponding system of differential equations a series of graphical presentations are presented. The comparison between linear and nonlinear system oscillatory, free and forced dynamics give some conclusions. Also, the analysis of the total mechanical energy of the system is analyzed. Using Mihailo Petrovic's theory of the mathematical phenomenology elements, phenomenological mappings in vibrations, signals, resonances and dynamical absorptions in models of two degrees of freedom system dynamics the abstractions of different real system dynamics are identified and presented by a Figure containing different physical models of the dynamical systems. By using the mathematical description of a chain mechanical system with two mass particles coupled by linear elastic and nonlinear elastic springs and two degrees of freedom expressed by corresponding generalized independent coordinates - translator displacements and corresponding analysis of solutions for free and forced vibrations series of corresponding two-frequency regimes and resonant states, as well as dynamical absorption states, are identified. By using these results and mathematical analogy and phenomenological mappings it is possible to make the corresponding analysis of the series of dynamics of other two degrees of freedom models and their dynamics (torsional system, double pendulum system, double electrical circuit).

\section{Acknowledgment}

Parts of this research were supported by the Ministry of Science, Education and Technological Development of the Republic of Serbia through the Mathematical Institute SANU, Belgrade, Grant OI 174001" Dynamics of hybrid systems with complex structures. Mechanics of materials", the Faculty of Mechanical Engineering, University of Niš, and OI 172015 through the Faculty of Physical Chemistry, University of Belgrade and III 45001 Institute of Chemistry, Technology and Metallurgy, University of Belgrade, Department of Catalysis and Chemical Engineering, Belgrade.

\section{References}

[1] HEDRIH (STEVANOVIĆ),K.R.: Modes of the Homogeneous Chain Dynamics, Signal Processing, Elsevier, 2006, 86, pp.2678-2702.

[2] HEDRIH (STEVANOVIĆ),K.R.: Dynamics of coupled systems. Nonlinear Analysis: Hybrid Systems, 2008, 2, pp.310-334.

[3] HEDRIH (STEVANOVIĆ),K.R.: Energy interaction between linear and nonlinear oscillators (Energy transient through the subsystems in the hybrid system), Ukr. Mat. Zhurn., 2008, 60, pp.796-814.

[4] KOLAR-ANIĆ,LJ., ČUPIĆ,Ž., VUKOJEVIĆ,V., ANIĆ,S.: Dinamika nelinearnih procesa (Dynamics of nonlinear processes), Fakultet za fizičku hemiju, Beograd, 2011, p. 403

[5] MITROPOLYSKIY,Yu.A.: Nonlinear Mechanics - Asymptotic Methods, Institut matematiki NAN Ukraini, Kiev, 1995, p. 397. (in Russian)

[6] MITROPOLYSKIY,Yu.A.: Problemi asimptoticheskoy teorii nestashionarnih kolebaniy (Problems of asymptotic theory of no stationary vibrations), Nauka Moskva, 1964. (in Russian).

[7] MITROPOLYSKIY,Yu.A., NGUYEN VAN DAO: Lectures on Asymptotic Methods of Nonlinear Dynamics, Vietnam National University Publishing House, Hanoi, 2003, p. 494.

[8] PETROVIĆ,M.: Fenomenološko preslikavanje (Phenomenological mapping), Srpska kraljevska akademija, Beograd, 1933, p. 33. (In Serbian)

[9] PETROVIĆ,M.: Elementi matematičke fenomenologije (Elements of mathematical phenomenology), Srpska kraljevska akademija, Beograd, 1911, p. 789. (In Serbian)

[10] http://elibrary.matf.bg.ac.rs/handle/123456789/476?localeattribute $=\mathrm{sr}$

[11] RAŠKOVIĆ,D.: Teorija oscilacija (Theory of Oscillations), Naučna knjiga, 1952. (In Serbian)

\section{Oscilatori: Fenomenološko preslikavanje i analogije - Prvi deo: Matematička analogija i lanci -}


apsorbciji, u tim modelima, dinamička apstrakcija različitih modela realnih sistema identifikovane su matematička i kvailitativne analogije. Matematički opis jednog mehaničkog lanca sa dvema materijalnim tačkama spregnutim linearnoelastičnom ili nelinearno elastičnim oprugama i sa dva stepena slobode kretanja je prikazan zajedno sa odgovarajućom alaizom kinetičkih parametara. Analizom odgovarajućih rešenja za sopstvene i prinudne dvofrekventne režime oscilacija i rezonantnih stanja, kao i stanja dinamičke apsorpcije došlo se do novih sazanja o interakciji modova u nelinearnoj dinamici. Korišćenjem matematičke analogije i fenomenološkog preslikavanja svojstvenih fenomena izučavanog mehaničkog sistema, pokazano je da se ta saznanja mogu koristiti za saznanja o fenomenima i svojstvima dinamika drugih apstrakcija realnih sistema modelima sistema sa dva stepena slobode oscilovanja (napr. dvojnog klatna, ili modela torzijskih oscilacija vratila sa dva diska, ili dvojnog električnog kola). I u najkraćem, analitički i numerički rezultati linearnih i nelinearnih dinamika sistema sa dva stepena slobode su prikazani kao univerzalni, koji se mogu preneti i na različite druge sisteme analogijama i preslikavanjima fenomena.

\title{
Oscillateurs: application phénoménologique et analogies - Première partie: analogie mathématique et chaînes -
}

Les nouveaux résultats analytiques et numériques pour la dynamique des systèmes linéaires et non linéaires à deux degrés de liberté de mouvement sont présentés. Pour les chaînes mécaniques on a étudié de façon analytique et numérique avec les comparaisons correspondantes des propriétés entre les régimes libres et les régimes forcés leurs oscillatoires dynamiques linéaires ainsi que celles non linéaires. On a présenté aussi l'analyse de l'énergie et le transfert d'énergie parmi les sous-systèmes. En utilisant la théorie de Mihailo Petrovic «Eléments de la phénoménologie mathématique» et "Application phénoménologique» chez oscillateurs, signaux , phénomènes de résonance et absorption dynamique dans ces modèles, l'abstraction dynamique des différents modèles chez les systèmes réels on a identifié les analogies mathématiques et qualitatives. La description mathématique d'une chaîne mathématique à deux points matériaux couplés par ressorts linéaires élastique ou non élastiques et à deux degrés de liberté de mouvement est présentée avec l'analyse correspondante des paramètres cinétiques. Par l'analyse des solutions adéquates pour les régimes des oscillations libres ou forcées à deux fréquences et des états de résonance ainsi que l'état de l'absorption dynamique on a obtenu de nouvelles connaissances sur l'interaction des modes dans la dynamique non linéaire. Par l'analogie mathématique et l'application phénoménologique des phénomènes du système étudié on a démontré que ces connaissances peuvent s'utiliser pour d'autres abstractions des systèmes réels par les modèles à deux degrés de liberté d'oscillations (par exemple chez la pendule double ou chez le modèle des oscillations torses d'ensouple à deux disques ou chez le double circuit électrique. En bref les résultats analytiques et numériques des systèmes dynamiques linéaires ou non linéaires à deux degrés de liberté sont présentés comme universels pouvant se transférer sur d'autres systèmes différents à l'aide des analogies ou des applications des phénomènes.

Mots clés: dynamique non linéaire, oscillations, oscillations propres, oscillations forcées, oscillateurs.

\section{Осцилляторы: феноменологическое отображение и аналогии - Часть I: математические аналогии и цепочки -}

\begin{abstract}
Здесь рекомендуемы новые аналитические и численные результаты по динамике линейных и нелинейных систем с двумя степенями свободы движения. Для механических цепей были исследованы, аналитически и численно со соответсвенными сравнениями между свойствами самостоятельных и принудительных режимов, колебательные линейные и нелинейные динамики в них. Здесь представлен и энергетический анализ динамики и перенос энергии между подсистемами. Используя теорию Михайла Петровича «Элементы математической феноменологии" и "Феноменологическое отображение", в колебаниях, в сигналах, в явлениях резонанса и динамического поглощения, в этих моделях динамическая абстракция различных моделей реальных систем была выявлена как математическая и качественная аналогии. Математическое описание механической цепи с двумя пунктами из композитного материала с линейно упругими или нелинейно упругими пружинами и с двумя степенями свободы движения показано вместе с соответствующим анализом кинетических параметров. Анализом соответствующих решений для собственных и вынужденных двухчастотных режимов колебаний и резонансных состояний, а в том числе и состояния динамического поглощения, мы выяснили что нужно знать о режимах взаимодействия в нелинейной динамике. С помощью математической аналогии и феноменологического отображения присущих явлений прилагаемой механической системы, было показано, что эти знания могут быть использованы для знаний о явлениях и свойствах динамики других абстракций реальных систем с моделями систем с двумя степенями свободы колебаний (например, модели двойного маятника или модели крутильных колебаний вала с двумя дисками, или модели двойной электрической цепи). Вкратце, аналитические и численные результаты линейных и нелинейных динамических систем с двумя степенями свободы представлены как универсальные, которые могут быть переданы в различные другие системы путём аналогий и отображений явлений.
\end{abstract}

